\title{
Conteúdo iônico em um testemunho de firn do Platô Antártico
}

\author{
Nicoli P. GERHARD¹, 2 , Jefferson C. SIMÕES², Isaías U. THOEN², Flávia A. TAVARES ${ }^{1,2}$, \\ Gino CASASSA ${ }^{3} \&$ Ronaldo T. BERNARDO²
}
1 Programa de Pós-Graduação em Geociências, Instituto de Geociências, Universidade Federal do Rio Grande do Sul. Av. Bento Gonçalves, 9.500, CEP 91.540-000, Porto Alegre, RS, Brasil (nicoligerhard@gmail.com).
2 Centro Polar e Climático, Instituto de Geociências, Universidade Federal do Rio Grande do Sul. Av. Bento Gonçalves, 9.500, CEP 91.540-000, Porto Alegre, RS, Brasil (jefferson.simoes@ufrgs.br, 00120894@ufrgs.br, flaviaalvestavares@hotmail.com, ronaldo.bernardo@ufrgs.br ).
${ }^{3}$ Universidad de Magallanes. Av. Bulnes 01855, Casilla 113-D, Punta Arenas, Chile
(g.casassa@geoestudios.cl).

Resumo. Este trabalho investiga o conteúdo iônico dos 28,73 m superiores do testemunho BR-IC-2 ( $88^{\circ} 01$ '21,3"S; 8204'21,7"W), coletado durante a travessia antártica chileno-brasileira no verão austral de 2004/05. As concentrações dos íons majoritários $\mathrm{Na}^{+}, \mathrm{K}^{+}, \mathrm{Mg}^{2+}, \mathrm{Ca}^{2+}, \mathrm{Cl}^{-}$, $\mathrm{NO}_{3}{ }^{-}$e $\mathrm{SO}_{4}{ }^{2-}$ e do ácido orgânico $\mathrm{H}_{3} \mathrm{CSO}_{3}{ }^{-}$(metanosulfonato - MS') foram determinadas por cromatografia iônica. A datação, baseada na correlação entre as concentrações de $\mathrm{Na}^{+}$e nssSO ${ }_{4}^{2-}$ (sulfato não proveniente de sal marinho), na razão isotópica $\delta D$ e na identificação de sinais de erupções vulcânicas (Pinatubo / Cerro Hudson em 1993, Agung em 1965 e possivelmente Bristol Island em 1936) constatou uma idade de 85 anos (período 1918-2003) para o testemunho, com precisão de \pm 3 anos. A partir da datação foi possível estabelecer a precipitação anual média nesse sítio: 0,15 m eq $\mathrm{H}_{2} \mathrm{O}$. Constatou-se uma contribuição de aerossóis de sais marinhos pouco expressiva e uma grande contribuição crustal e biogênica, indicada pelas concentrações de nssCa ${ }^{2+}$ e nssSO ${ }_{4}^{2}$, respectivamente. O alto valor da razão $\mathrm{Cl}^{-} / \mathrm{Na}^{+}(4,96)$ indica que outros fatores, além da contribuição de sal marinho, contribuem para as concentrações desses íons, como a entrada ou formação de $\mathrm{HCl}$ e a menor depleção do $\mathrm{Cl}^{-}$. As concentrações de $\mathrm{K}^{+}$e $\mathrm{Mg}^{2+}$, apesar de apresentarem correlação fraca com os outros íons, são de origem marinha. O MS mostra valores pouco expressivos para a região e o $\mathrm{NO}_{3}{ }^{-}$não tem correlação com os outros íons, devido à complexidade das fontes, já que este íon se apresenta como um aerossol secundário.

Palavras-chave. aerossóis, cromatografia iônica, Antártica, glacioquímica.

\begin{abstract}
IONIC CONTENT IN A FIRN CORE FROM THE ANTARCTIC PLATEAU. This work investigates the ionic content of the upper $28.73 \mathrm{~m}$ of the BR-IC-2 core $\left(88^{\circ} 01^{\prime} 21.3^{\prime \prime} \mathrm{S}\right.$; $\left.82^{\circ} 04^{\prime} 21.7^{\prime \prime} \mathrm{W}\right)$ collected during the Chilean-Brazilian Antarctic traverser in the austral summer of 2004/05. The concentrations of the major ions $\mathrm{Na}^{+}, \mathrm{K}^{+}, \mathrm{Mg}^{2+}, \mathrm{Ca}^{2+}, \mathrm{Cl}^{-}, \mathrm{NO}_{3}{ }_{3}^{-}$and $\mathrm{SO}_{4}{ }^{2-}$ and organic acid $\mathrm{H}_{3} \mathrm{CSO}_{3}{ }^{-}$(methanesulfonate - MS') were determined by lon chromatography. Dating, based on the correlation between $\mathrm{Na}^{+}$and $\mathrm{nssSO}_{4}{ }^{2-}$ (non sea salt sulfate) concentrations, the $\delta \mathrm{D}$ isotopic ratio and the identification of volcanic eruption layers (Pinatubo / Cerro Hudson in 1993, Agung in 1965 and possibly Bristol Island in 1936) found an age of 85 years (1918-2003) for the core, with precision of \pm 3 years. From this dating, it was possible to establish the mean annual precipitation at this site: $0.15 \mathrm{~m}$ eq $\mathrm{H}_{2} \mathrm{O}$. A low contribution of sea salts aerosols and a large crustal and biogenic contribution were found, indicated by the concentrations of $\mathrm{nssCa}^{2+}$ and nss $\mathrm{SO}_{4}{ }_{4}^{2-}$, respectively. The high value of the $\mathrm{Cl}^{-} / \mathrm{Na}^{+}$ratio (4.96) indicates that factors other than the contribution of sea salt contribute to the concentrations of these ions, such as the input or formation of $\mathrm{HCl}$ and the lower depletion of $\mathrm{Cl}^{-}$. The $\mathrm{K}^{+}$and $\mathrm{Mg}^{2+}$ concentrations, although poorly correlated with other ions, are of marine origin. $\mathrm{MS}^{-}$shows low values for the region $\mathrm{and} \mathrm{NO}_{3}{ }^{-}$has no correlation with other ions, due to complex sources since this ion appears as a secondary aerosol.
\end{abstract}

Keywords. aerosols, Ion chromatography, Antarctic, glaciochemistry. 


\section{Introdução}

Um dos mais icônicos e valiosos conjunto de dados científicos do sistema Terra é obtido pelos registros químicos e isotópicos de testemunhos de gelo (Wolff, 2012). O estudo dos parâmetros químicos da precipitação e acumulação de neve nos mantos de gelo das últimas centenas de milhares de anos fornecem uma ferramenta única para obtenção de informações da composição da atmosfera pré-industrial e sua variabilidade natural no passado (Legrand \& Mayewski, 1997). Isso é possível, em grande parte, porque numerosas medidas químicas e físicas podem ser realizadas a qualquer profundidade nos mantos de gelo e geleiras e porque a transformação de neve em firn e gelo fornece dois conjuntos básicos de informações atmosféricas: primeiro, quando o firn transforma-se em gelo, são formadas bolhas de ar que armazenam gases traço atmosféricos,

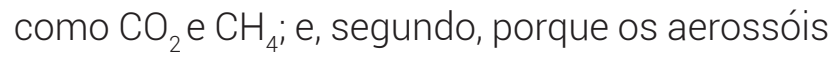
e gases solúveis em água podem ser capturados durante a precipitação de neve (Kreutz \& Koffman, 2013).

Os primeiros testemunhos de gelo a serem obtidos foram coletados na década de 1950 e a partir de então, nas décadas seguintes, com o desenvolvimento contínuo das perfurações, com as numerosas organizações logísticas de apoio financeiro e com as colaborações internacionais, a comunidade científica tem extraído informações valiosas desses testemunhos sobre o clima passado e as mudanças ambientais (Jouzel, 2013).

Aqui, apresentamos os dados de conteúdo de química iônica em um testemunho de neve/ firn de 40,55 m coletado no Platô Antártico

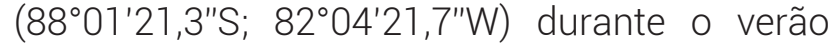
austral de 2004/2005, para determinar a variabilidade temporal desses dados.

\section{Metodologia}

\subsection{Trabalho de campo}

A coleta do testemunho de gelo BR-IC-2 (IC-2 a partir daqui), juntamente com a coleta de outros 5 testemunhos (Fig. 1), foi realizada por uma equipe chileno-brasileira em uma travessia do manto de gelo da Antártica no verão austral de 2004/2005 e fez parte do Programa ITASE (International Trans-Antarctic Scientific Expedition). Esse programa teve como objetivos principais a determinação da variabilidade espacial e temporal do clima antártico (e.g., eventos extremos, variações de acumulação de neve, temperatura do ar, circulação atmosférica) e as mudanças ambientais que impactaram a Antártica (e.g., variações na extensão do gelo marinho, produtividade oceânica, atividade antropogênica, atividade vulcânica) nos últimos 200 anos (Mayewski \& Goodwin, 1997).

O sítio do testemunho IC-2 (8801'21,3"S, $82^{\circ} 04^{\prime} 21,7^{\prime \prime} \mathrm{W}, 2.621 \mathrm{~m}$ de altitude no Platô Antártico) (Fig. 2) está a $220 \mathrm{~km}$ do Polo Sul geográfico, próximo a cerca de $300 \mathrm{~km}$ das montanhas Transantárticas. 0 testemunho de gelo, que foi obtido entre 11 e 13 de dezembro de 2004, atingiu 40,55 m profundidade, em um local com temperatura média (estimada com medida a $10 \mathrm{~m}$ de profundidade por um termistor estabilizado durante $24 \mathrm{~h}$ ) de $45^{\circ} \mathrm{C}$. A posição geográfica do sítio de amostragem foi determinada por um aparelho portátil de GPS, com precisão de 30 m (Lindau et al., 2016).

Foram coletadas ao total 45 seções de aproximadamente $1 \mathrm{~m}$ de comprimento cada. A perfuração inicial do IC-2 foi interrompida na seção de número 22 (devido a problemas na perfuradora) e um novo poço, distante $30 \mathrm{~cm}$, foi perfurado. Do segundo poço, foram descartadas as primeiras 21 seções e o armazenamento dos testemunhos iniciou na seção 22. Devido a esse procedimento, o registro do testemunho foi dividido em: testemunho $A$, da seção 1 à seção 22A, e testemunho B, da seção 22B à seção 45.

As seções do testemunho foram seladas em sacos de polietileno e pesadas ainda em campo com uma balança eletrônica de precisão de 0,1 g, modelo BS3000A da Bioprecisa, para a posterior determinação das densidades de cada seção (Lindau et al., 2016). A seguir foram colocados em caixas de isopor e ao final da travessia, transportados por via aérea da estação chilena Parodi ( $80^{\circ} 18^{\prime} \mathrm{S}$; $81^{\circ} 22^{\prime} \mathrm{W}$ ) em Patriot Hills até a cidade de Punta Arenas no Chile, em seis horas de voo sem refrigeração. Dessa cidade, 
os testemunhos foram transportados de avião sobre refrigeração até Nova Iorque e, após, foram levadas por caminhão frigorífico até Bangor, no Estado do Maine (EUA), onde ficaram guardados em câmara frigorífica a $-20^{\circ} \mathrm{C}$ até o momento da preparação para as análises (Schwanck, 2012).

\subsection{Densidade e estratigrafia}

A partir do peso obtido em campo em cada seção do testemunho e com as informações das dimensões lineares, comprimento e diâmetro, foi possível calcular o perfil da densidade pela profundidade (Fig. 3). A densidade nos permite corrigir a profundidade do testemunho para metros equivalente de $\mathrm{H}_{2} \mathrm{O}$ (multiplicando $\mathrm{O}$ comprimento de cada seção pela sua densidade correspondente) e calcular a taxa de precipitação de neve local. A taxa média de densidade do testemunho IC-2 é de 0,56 $\mathrm{g} \mathrm{cm}^{-3}$, com valores entre 0,34 e $0,65 \mathrm{~g} \mathrm{~cm}^{-3}$. O comprimento total do testemunho IC-2 foi de 40,55 m (ou 21,74 m eq $\mathrm{H}_{2} \mathrm{O}$ ). Este trabalho examina as informações químicas somente até a profundidade de 14,35 m eq $\mathrm{H}_{2} \mathrm{O}$ (ou seja, os 28,59 m superiores da perfuração).

A estratigrafia do IC-2 apresenta uma camada muito superficial de neve. De acordo com Cuffey \& Paterson (2010), a neve é considerada o material que não sofreu modificações após sua precipitação e o firn refere-se ao material em estágio intermediário de transformação, ocorrendo entre as densidades de 0,4 a 0,83 g $\mathrm{cm}^{-3}$, quando a partir de então torna-se gelo. Aqui observa-se que logo no primeiro metro, ainda com a densidade de $0,4 \mathrm{~g} \mathrm{~cm}^{-3}$, já há características de firn no testemunho. Ao longo de todo o testemunho existem camadas finas de escarcha de profundidade (depth hoar), que são camadas menos densas que o firn, com densidades entre 0,1 e 0,3 $\mathrm{g} \mathrm{cm}^{-3}$ (Cuffay \& Patterson, 2010).

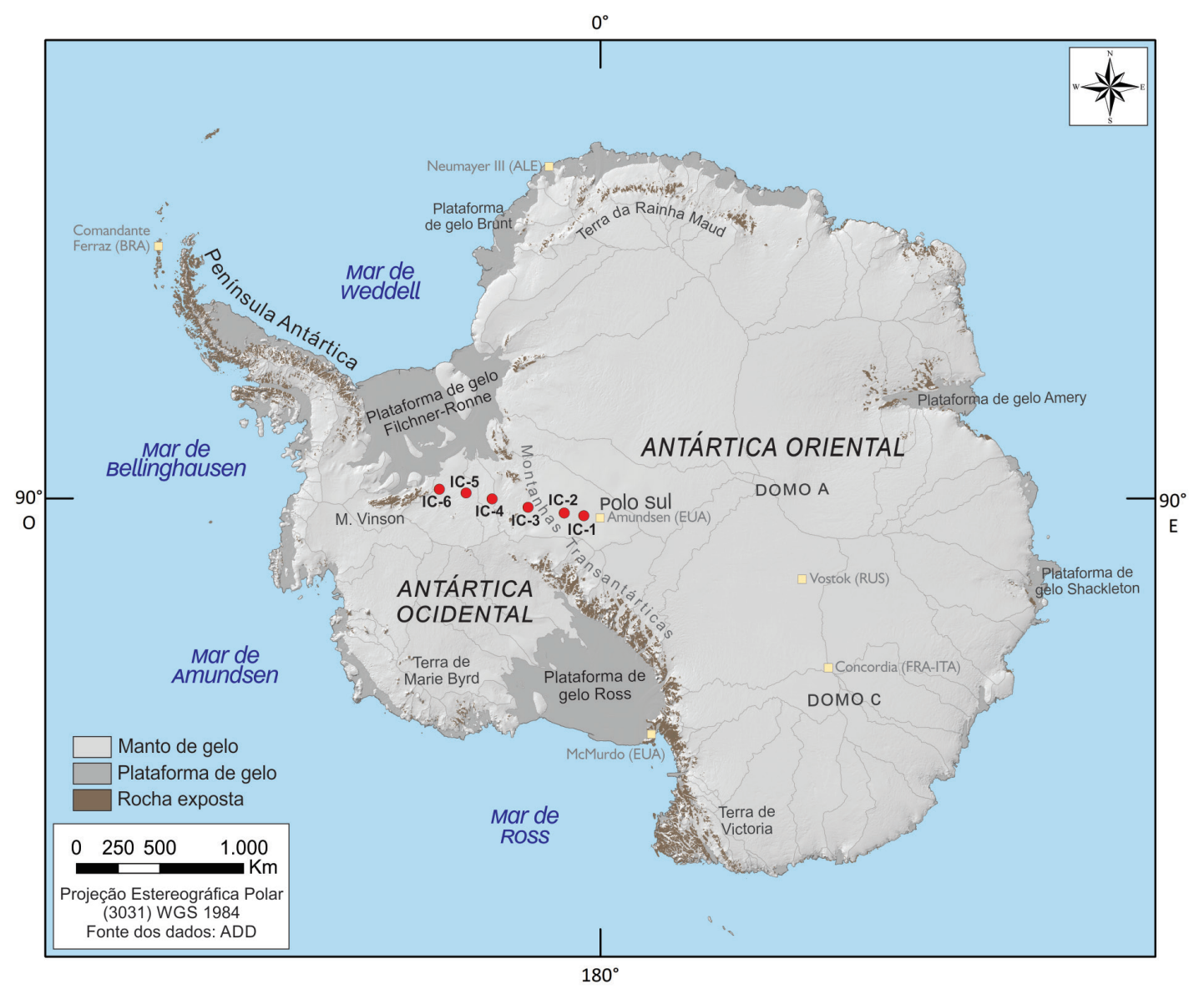

Figura 1. Mapa de localização dos testemunhos de gelo obtidos durante a travessia chileno-brasileira no verão austral de 2004/2005 (IC-1 a IC-6). Linhas cinzas fracas marcam os divisores de bacias de drenagem do manto de gelo antártico. Fonte: autores.

Figure 1. Location map of ice cores (IC-1 to IC-6) obtained during the 2004/2005 Chilean-Brazilian Antarctic traverse in the 2004/2005 austral summer. Light grey lines mark the Antarctic ice sheet drainage basin dividers. 


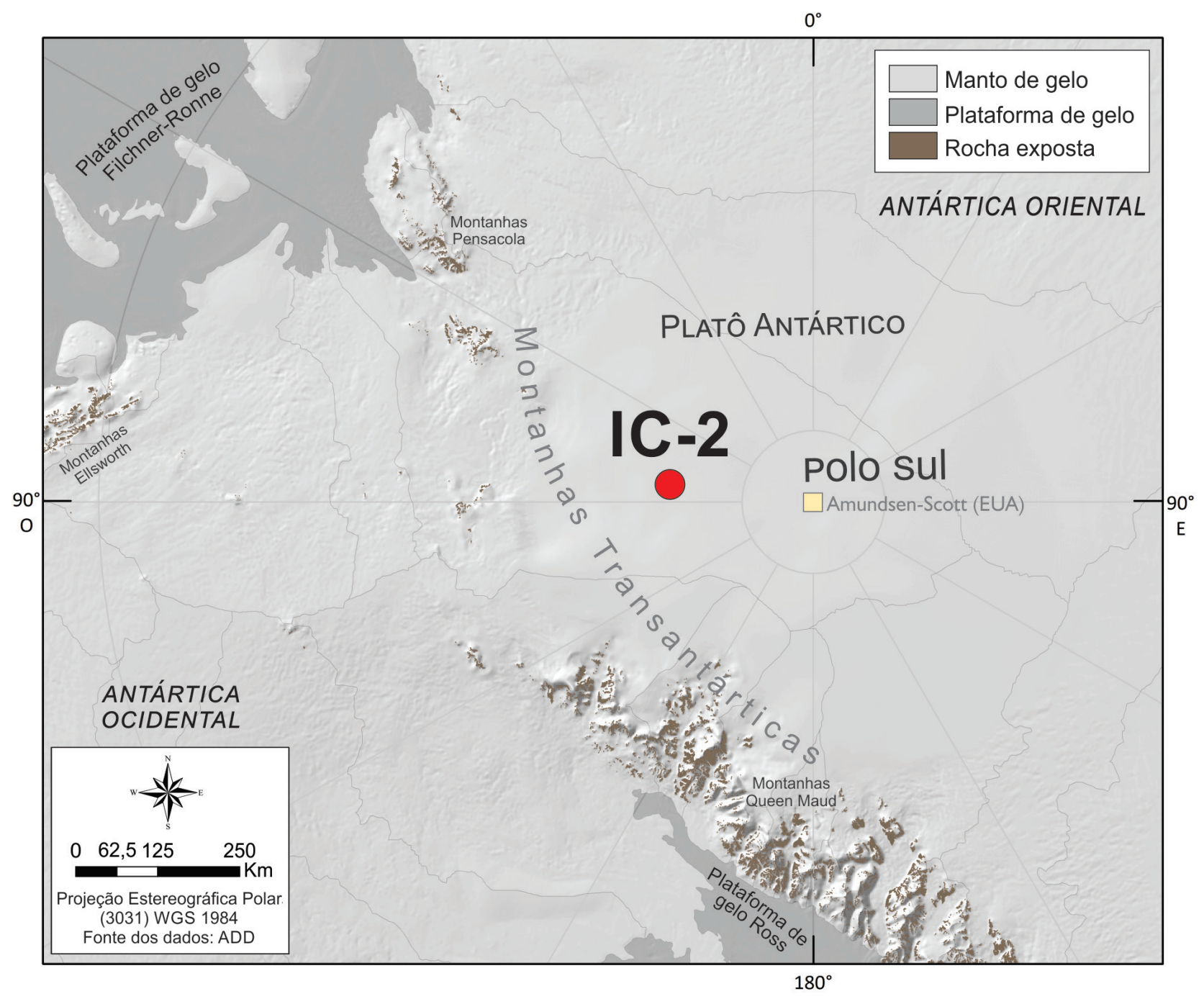

Figura 2. Mapa de localização do testemunho de gelo IC-2 no platô do manto de gelo da Antártica Oriental. Figure 2. The IC-2 ice core site in the East Antarctic ice sheet plateau.

\subsection{Subamostragem}

\subsubsection{Descontaminação}

Durante a perfuração, os testemunhos podem sofrer vários tipos de contaminações, que têm origem em diferentes contribuições. A principal é da parede de retenção de fluidos, quando são querosene, fréon e acetato de n-butila, utilizados para prevenir o fechamento do poço de perfuração em grandes profundidades. Mas contaminações também podem originarse a partir da broca, do cabo, do manuseio, da embalagem e armazenamento do testemunho (Candelone et al., 1994).

O testemunho deste trabalho é raso e, portanto, não foram adicionados fluidos no poço de perfuração, mas, mesmo assim, é necessário realizar o processo de descontaminação das seções antes da subamostragem (Schwanck, 2012).

Alguns dias antes do início da descontaminação, as caixas de isopor com os testemunhos de gelo antárticos foram transferidas do frigorífico da cidade de Bangor para a câmara fria do $\mathrm{CCl}$ (Climate Change Institute, Orono, ME/EUA). No laboratório, continuaram sendo mantidas a $-20^{\circ} \mathrm{C}$, em um sistema automático de resfriamento e com registro contínuo das oscilações de temperatura (Schwanck, 2012).

A etapa de descontaminação foi executada dentro dessa câmara frigorífica, onde os pesquisadores realizaram o trabalho utilizando botas, luvas, gorros e macacões polares (Silva, 2011). A descontaminação ocorreu em uma mesa 


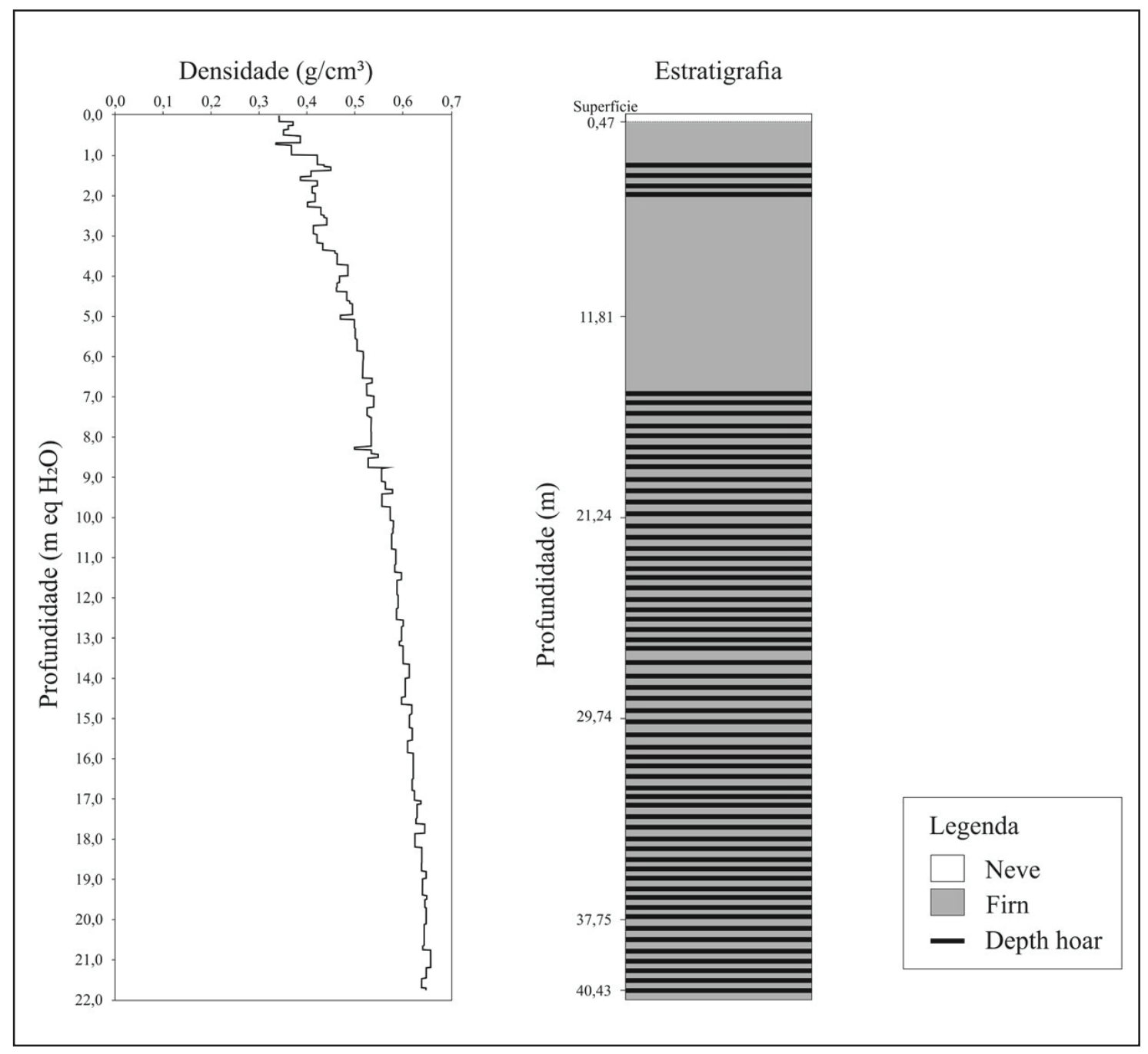

Figura 3. Perfis da densidade e estratigráfico do testemunho IC-2. Note que neste trabalho são reportados dados químicos apenas até a profundidade de $14,35 \mathrm{~m}$ eq $\mathrm{H}_{2} \mathrm{O}$.

Figure 3. Density and stratigraphic profiles of the IC-2 core. Note that in this work chemical data are reported only up to the depth of $14.35 \mathrm{~m}$ eq $\mathrm{H}_{2} \mathrm{O}$.

de fluxo laminar horizontal, previamente limpa com metanol. A mesma solução foi utilizada para limpar os equipamentos em uso: faca de cerâmica, canivete e régua. Esse procedimento de limpeza foi realizado diariamente, sempre antes do início dos trabalhos (Silva, 2011). Durante todo o manuseio das seções do testemunho usaram-se também luvas de polietileno (Lindau et al., 2016).

Todas as seções dos testemunhos tiveram suas laterais serradas com uma lâmina de aço acoplada a uma serra elétrica, reduzindo a seção cilíndrica (com aproximadamente $8,25 \mathrm{~cm}$ de diâmetro), para uma forma prismática de base quadrada, com lados de aproximadamente $4,4 \mathrm{~cm}$ (Lindau et al., 2016). As extremidades de cada seção, por serem os locais mais susceptíveis à contaminação (Schwanck, 2012), foram raspadas com as facas cerâmicas, retirando-se camadas de 2 a 4 mm (Lindau et al., 2016).

Concluindo esta etapa, os pedaços do testemunho descontaminado foram acondicionados em tubos de Plexiglas (acrílico), respeitando o posicionamento estratigráfico original, condição necessária para a correta interpretação dos dados. Os tubos eram então envoltos em sacos plásticos depositados dentro de cilindros revestidos com uma membrana com propriedade de isolamento térmico e, após, transportados até uma sala limpa de classe 100 (ISO14644:1999), o que levava no máximo 2 min (Schwanck, 2012), onde então passaram pelo processo de derretimento contínuo. 


\subsubsection{Sistema de derretimento contínuo}

O derretimento das seções foi realizado em um laboratório limpo de classe 100, pelo processo de fusão contínua do $\mathrm{CCl}$ (Climate Change Institute), descrito por Osterberg et al. (2006), como mostrado na figura 4.

Esse sistema de fusão de testemunhos de gelo é constituído pelo método de derretimento contínuo com amostragem discreta (continuous melting with discrete sampling - CMDS) que coleta amostras de água coregistradas, contínuas, de alta resolução e discretas, a partir de um dispositivo de fusão de gelo/firn. 0 sistema combina a limpeza e a alta resolução de amostragem de fusão contínua com flexibilidade e precisão da amostragem discreta convencional. Com as amostras coletadas por ele é possível fazer análise de íons maiores por cromatografia de troca iônica (do inglês, Ion Exchange Chromatograpy - IEC), elementos traço por espectrometria de massa por plasma acoplado indutivamente (do inglês, Inductively Coupled Plasma Mass Spectrometry - ICPMS), e isótopos de oxigênio e hidrogênio por espectrometria de massa por razão isotópica (do inglês, Isotope-ratio Mass Spectrometry - IRMS) (Osterberg et al., 2006).
Com a finalidade de determinar o nível de contaminação de fundo e a qualidade da limpeza no sistema, antes do início dos trabalhos diários, era bombeada água Milli- $Q^{\circledR}$ em todo o sistema de derretimento durante $30 \mathrm{~min}$, coletadas três amostras dessa água para análise de brancos, e ao fim de cada ciclo de derretimento, esse processo era repetido (Thoen, 2017).

Dentro de um ambiente refrigerado a -20 ${ }^{\circ} \mathrm{C}$, o testemunho foi submetido à fusão, respeitando a ordem estratigráfica (mantendo a mesma ordem e codificação utilizada em campo), que ocorreu por contato gravitacional entre a base do testemunho e um disco de $\mathrm{Ni}^{270}$. Este disco, aquecido entre 15 e $25^{\circ} \mathrm{C}$, levou à fusão das seções por condução térmica, que como apresentavam densidades diferentes, tiveram taxas de fusão entre 1,5 e $3 \mathrm{~cm} \mathrm{~min}^{-1}$. 0 disco de $\mathrm{Ni}^{270}$ apresenta $70 \mathrm{~mm}$ de diâmetro e $3 \mathrm{~mm}$ de espessura e ranhuras radiais de 0,2 $\mathrm{mm}$, por onde a água descongelada fluía. O seu sistema de drenagem é constituído de um anel concêntrico de $30 \mathrm{~mm}$ de diâmetro e $1 \mathrm{~mm}$ de elevação, que divide o fluxo da água em dois canais de politetrafluoretileno independentes. A fração coletada pelo canal interno do disco (fração mais preservada) é destinada para as análises de IEC e ICP-MS, acondicionada em frascos limpos
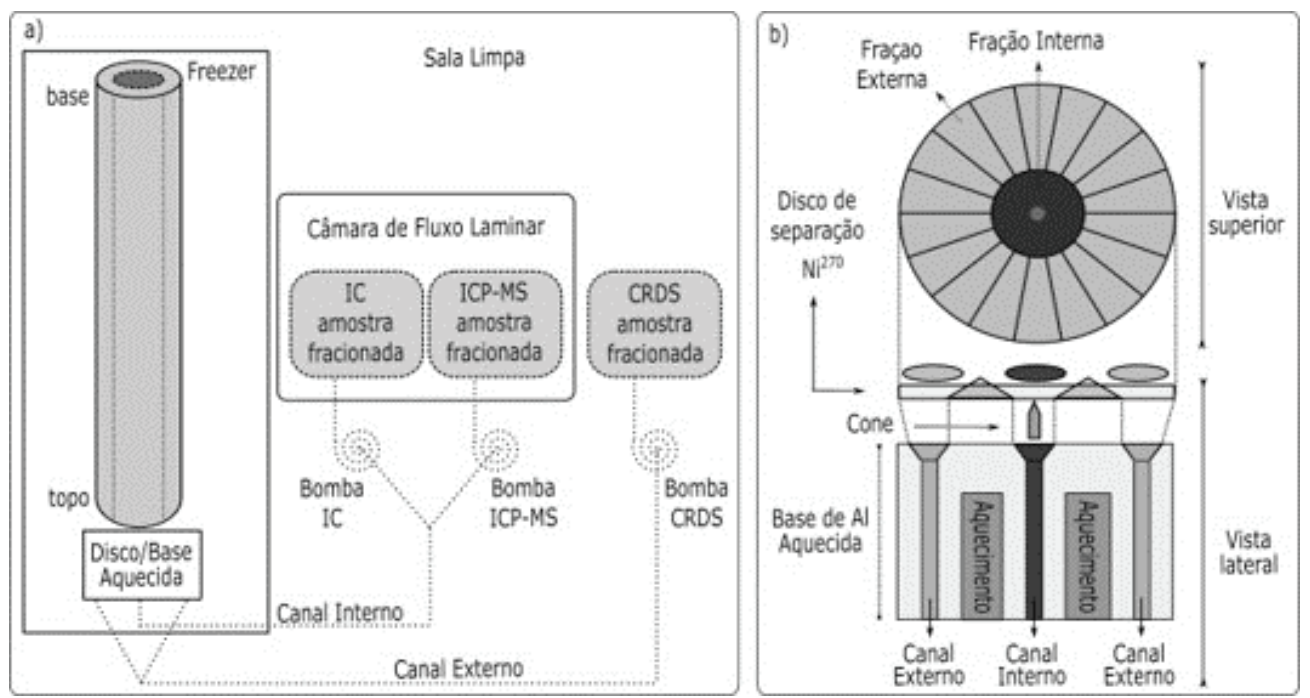

Figura 4. Metodologia usada neste trabalho para fusão e subamostragem do testemunho IC-2 seguindo Osterberg et al. (2006) e modificado por Thoen (2017).

Figure 4. Methodologia used in this work for melting and subsampling of the IC-2, following Osterberg et al. (2006), and modified by Thoen (2017). 
de propileno que foram previamente limpos com três enxágues e $24 \mathrm{~h}$ de molho com água deionizada Milli-Q ${ }^{\circledR}$ (Millipore, EUA). Para o IEC foram destinados $5 \mathrm{~mL}$ e para o ICP-MS, $3 \mathrm{~mL}$, de amostras para as análises. A fração coletada pelo canal externo e mais exposta do testemunho foi destinada à análise isotópica, acondicionada em frascos de $40 \mathrm{~mL}$ feitos de PEAD (Lindau et al., 2016; Osterberg et al., 2006; Thoen, 2017).

\subsection{Análises químicas}

As primeiras 200 amostras do IC-2 foram analisadas no laboratório do $\mathrm{CCl}$, Maine, e sua metodologia e dados foram apresentados por Lindau et al. (2016). O conteúdo iônico dessas amostras foi determinado por cromatografia iônica em um equipamento Dionex 500, onde um amostrador automático direcionava as amostras para dois sistemas, cátions e ânions (Tab. 1).

De acordo com Lindau et al. (2016), uma atmosfera inerte de gás hélio foi utilizada nos reservatórios de eluente e de água deionizada Milli- $Q^{\circledR}$ com resistividade de 18,2 M $\Omega$. Os sistemas eram calibrados semanalmente com cinco soluções padrão preparadas a partir de soluções estoque da Ultra Scientific, EUA, e os resultados conferidos com a solução de referência ION-92, do National Water Research Institute, Canadá.

Para estabelecer os limites de detecção do método analítico, foi utilizada a metodologia EPA 300.1 - Determination of inorganic anions in drinking water by ion chromatography onde sete soluções de água deionizada são processadas e analisadas como as amostras. Esses limites foram definidos entre os valores de
0,3 $\mu \mathrm{g} \mathrm{L}^{-1}$ (limite de detecção do potássio) e 1,8 $\mu \mathrm{g}$ $\mathrm{L}^{-1}$ (limite de detecção para cloreto) (Lindau et al., 2016).

As análises das outras 950 amostras do testemunho IC-2, foram realizadas no laboratório limpo de classe 7 (ISO 14644-1:1999) do CPC, UFRGS. O método analítico utilizado é descrito por Thoen (2017).

Os cátions e ânions foram determinados por cromatografia iônica utilizando dois equipamentos, um Dionex ${ }^{\mathrm{TM}}$ ICS-2000 combinado com um ICS-2100 (Tab. 2), dimensionados com uma coluna de $2 \mathrm{~mm}$ de diâmetro, acoplados com um modo de injeção automatizada por um amostrador (Dionex ${ }^{\mathrm{TM}}$, modelo AS-DV). Os loops de injeção de amostras foram fixados em $200 \mu \mathrm{L}$ e a separação dos analitos desenvolveu-se de acordo com as concentrações dos gradientes de eluentes de cada coluna.

Segundo Thoen (2017), a determinação de quantidades traço nos sistemas de IC exige que a flutuação da linha de base seja baixa e controlada, e a condutividade total (absoluta) permaneça sempre baixa para garantir a sensibilidade necessária. Para isso, é definido um período de 50 horas de estabilização prévia nos cromatógrafos. Assim, o background de condutividade obtido quando das análises das amostras do testemunho IC-2 foi abaixo de 0,6 $\mu \mathrm{S} \mathrm{cm}{ }^{-1}$ e $0,3 \mu S \mathrm{~cm}^{-1}$, para ânions e para cátions, respectivamente.

No controle de qualidade, utilizou-se no laboratório água deionizada Milli- ${ }^{\circledR} \mathrm{com}$ resistividade de $18,2 \mathrm{M} \Omega$ a $25^{\circ} \mathrm{C}$, e todos os materiais de laboratório manipulados (frascos, pinças, embalagens, ponteiras, vidros) foram previamente descontaminados seguindo um

Tabela 1. Configuração do equipamento analítico Cromatógrafo lônico DIONEX 500 do CCI (extraído de Lindau et al., 2016).

Table 1. Configuration of the CCI analytic equipment DIONEX 500 lonic Cromatograph (extracted from et al., 2016)

\begin{tabular}{|c|c|c|}
\hline Sistema & Cátions & Ânions \\
\hline Loop de injeção & $500 \mu \mathrm{L}$ & $500 \mu \mathrm{L}$ \\
\hline Fluxo & $1 \mathrm{~mL} \mathrm{~min}^{-1}$ & $1 \mathrm{~mL} \mathrm{~min}^{-1}$ \\
\hline Eluente & MSA (20 mM isocrático) & $\mathrm{KOH}$ (gradiente de $1 \mathrm{mM}$ a $8 \mathrm{mM}$ ) \\
\hline Coluna de guarda & - & AG-11 \\
\hline Coluna Analítica & CS-12A & AS-11 \\
\hline Supressora & CSRS-300 & ASRS-300 \\
\hline Detector & CD20 & CD20 \\
\hline
\end{tabular}


Tabela 2. Configuração do equipamento analítico Cromatógrafo lônico Dionex TM ICS-2000 combinado com um ICS-2100. Table 2. Configuration of analytical equipment Dionex ${ }^{T M}$ ICS-2000 Chromatograph combined with an ICS-2100.

\begin{tabular}{|c|c|c|}
\hline Sistema & Cátions & Ânions \\
\hline Cromatógrafo & ICS-2100 Dionex ${ }^{\mathrm{TM}}$ & ICS-2000 Dionex ${ }^{\mathrm{TM}}$ \\
\hline Loop de injeção & $200 \mu \mathrm{L}$ & $200 \mu \mathrm{L}$ \\
\hline Gradiente de Eluente & $6-16$ mMolar & $13-40$ mMolar \\
\hline Fluxo de Eluente & $0.25 \mathrm{~mL} \mathrm{~min}^{-1}$ & $0.25 \mathrm{~mL} \mathrm{~min}^{-1}$ \\
\hline Eluente & Ácido metanosulfônico & Hidróxido de potássio \\
\hline Coluna de separação & Ion $\mathrm{Pac}^{\circledR} \mathrm{CS} 192 \mathrm{~mm}$ & Ion $\mathrm{Pac}^{\circledR} \mathrm{AS} 182 \mathrm{~mm}$ \\
\hline Corrente de supressora & $6 \mathrm{~mA}$ & $22 \mathrm{~mA}$ \\
\hline Tipo de Supressora & CERS500 $2 \mathrm{~mm}$ & AERS500 $2 \mathrm{~mm}$ \\
\hline Detector & CD20 & CD20 \\
\hline Pressão de trabalho & \pm 2000 PSI & \pm 1900 PSI \\
\hline Detector de temperatura & $35 \pm 0,1^{\circ} \mathrm{C}$ & $35 \pm 0,1^{\circ} \mathrm{C}$ \\
\hline Detector de background & $<0.3 \mu \mathrm{S} \mathrm{cm}^{-1}$ (typical) & $<0.6 \mu \mathrm{S} \mathrm{cm}^{-1}$ (typical) \\
\hline Tempo de corrida & $27 \mathrm{~min}$ & $27 \mathrm{~min}$ \\
\hline Sistema de análise de dados & Chromeleon $7.2^{\mathrm{TM}}$ software & Chromeleon $7.2^{\mathrm{TM}}$ soft \\
\hline
\end{tabular}

protocolo de limpeza interno, baseado em ciclos sucessivos de enxagues vigorosos em água purificada intercalados com períodos de repouso de 1 a 2 dias em imersão (Thoen, 2017). A manipulação de amostras e materiais foi realizada em ambiente limpo controlado em capela de fluxo laminar classe 5 (ISO 146441:1999) (Thoen, 2017).

Conforme Thoen (2017), para a calibração do sistema de análises de cromatografia iônica são utilizadas soluções padrão de trabalho (que são amostras de valores conhecidos e certificados dentro da sequência, diluídos em água) que criam os pontos de calibração de concentração conhecida analisada e têm resposta quanto à intensidade do sinal medido. Na construção da curva de calibração de cada analito, foram utilizados cinco a sete pontos de calibração com concentrações diferentes para definir o intervalo de quantificação, que é a faixa de concentração entre o limite inferior de quantificação instrumental e o limite superior definido em função da linearidade - visualizada nas curvas de calibração e confirmada pelo coeficiente de determinação $\left(r^{2}\right)$ - e da concentração esperada nas amostras. O cálculo de concentração das amostras foi realizado pela função de calibração linear (método dos mínimos quadrados), e em alguns casos, utilizadas funções quadráticas, como no $\mathrm{K}^{+}$, pois forneceram menores incertezas analíticas.

A sensibilidade é representada pela inclinação da linha de regressão na curva de calibração. Quanto maior essa inclinação, menor a variação na concentração, o que permite a utilização de limites de detecção baixos (Thoen, 2017). O MDL apresenta o limite de detecção do método, sendo associado à sensibilidade do método. Para defini-lo, foram realizados testes de sensibilidade instrumental antes de iniciar as análises das amostras de interesse.

A média de brancos representa o controle do processamento (limpeza e discretização) do testemunho em amostras analisáveis. A repetibilidade foi realizada pelo processamento de 8 replicatas de água previamente preparadas. A precisão intermediária e a exatidão foram estimadas por uma análise estatística das amostras de controle, utilizadas para checagem de recuperação em controle analítico (Thoen, 2017). Os erros negativos encontrados para $\mathrm{K}^{+}, \mathrm{H}_{3} \mathrm{CSO}_{3}^{-}, \mathrm{NO}_{3}^{-}, \mathrm{SO}_{4}^{2-}$ podem ser associados à menor precisão analítica, pois os intervalos de trabalho estão muito próximos dos limites de detecção. A tabela 3 traz as informações da calibração utilizada no método de análises. 
Tabela 3. Parâmetros de calibração e estimativa de incertezas do sistema de cromatografia iônica usado nesta investigação. Obs.: n.d. = não determinado.

Table 3. Calibration parameters and uncertainty estimation of the ion chromatography system used in this investigation. Obs.: n.d. = not determined.

\begin{tabular}{|c|c|c|c|c|c|c|c|c|}
\hline Variável & $\mathrm{Na}^{+}$ & $\mathbf{K}^{+}$ & $\mathrm{Mg}_{2}^{+}$ & $\mathrm{Ca}_{2}^{+}$ & $\mathrm{H}_{3} \mathrm{CSO}_{3}^{-}$ & $\mathrm{Cl}^{-}$ & $\mathrm{NO}_{3}^{-}$ & $\mathrm{SO}_{4}{ }^{2-}$ \\
\hline \multirow[t]{2}{*}{ Intervalo $\left(\mu \mathrm{g} \mathrm{L}^{-1}\right)$} & $2,0-$ & $0,4-$ & $0,3-$ & $1,0-$ & $0,5-40$ & $4,0-$ & $2,5-$ & $2,0-$ \\
\hline & 200 & 40 & 32 & 40 & & 320 & 200 & 160 \\
\hline Calibração RSD (\%) & 3,51 & 5,03 & 5,31 & 4,56 & 8,63 & 3,26 & 6,66 & 5,67 \\
\hline Linearidade $\mathbf{r}^{2}(\%)$ & 0,9990 & 0,9983 & 0,9982 & 0,9984 & 0,9950 & 0,9992 & 0,9970 & 0,9978 \\
\hline Sensibilidade & 0,0083 & 0,0060 & 0,0152 & 0,0093 & 0,0023 & 0,0093 & 0,0045 & 0,0061 \\
\hline MDL $\left(\mu g \mathrm{~L}^{-1}\right)$ & 0,1 & 0,1 & 0,1 & 0,5 & 0,3 & 0,3 & 1,2 & 1,8 \\
\hline Brancos $\left(\mu g \mathrm{~L}^{-1}\right)$ & 2,2 & 1,3 & 0,9 & 1,0 & 1,4 & 3,6 & 6,1 & n.d. \\
\hline Repetibilidade CV & 1,4 & 0,8 & 1,0 & 4,6 & 3,8 & 2,1 & 2,8 & 2,3 \\
\hline \multicolumn{9}{|l|}{$(\%)$} \\
\hline Precisão & 1,4 & 4,2 & 2,9 & 4,6 & 5,8 & 3,9 & 3,3 & 3,0 \\
\hline \multicolumn{9}{|l|}{ intermediária } \\
\hline \multicolumn{9}{|l|}{ CV (\%) } \\
\hline Erro (\%) & $+0,2$ & $-2,7$ & $+2,0$ & $+0,4$ & $-1,9$ & $+1,4$ & $-5,0$ & $-4,3$ \\
\hline
\end{tabular}

\section{Resultados}

Das 1755 amostras do IC-2, 1150 foram analisadas pela técnica analítica de cromatografia iônica, das quais as primeiras 200 amostras no Climate Change Institute (CCl), da Universidade do Maine, e as outras 950 amostras, no laboratório do Centro Polar e Climático (CPC) da UFRGS.

As amostras de números 630 até 688 foram desconsideradas da análise, pois identificou-se que elas sofrerem sobreposição com as amostras 689 até 747 . Essa sobreposição ocorreu quando foi iniciada a coleta do testemunho B. Para que nenhum dado fosse perdido, os pesquisadores de campo escolheram iniciar a perfuração em uma seção anterior. Assim, pelo exame dos gráficos de $\mathrm{Na}^{+}, \mathrm{nssSO}_{4}{ }^{2-}$ e $\delta \mathrm{D}$ (Tavares, 2019) (Fig. 5) e nos dados gerados em tabelas, foi identificado o ponto aproximado onde isso aconteceu, sendo então excluídos os dados correspondentes ao testemunho A. Em campo foi registrado que o testemunho atingiu 42,92 m de profundidade, mas descontando as amostras sobrepostas, chega-se a uma profundidade de 40,55 m. No total, este artigo considera os resultados de 1.091 amostras, representando os 28,59 m superiores do testemunho IC-2.

\subsection{Dados iônicos}

Aqui, são apresentados os resultados das análises de cromatografia iônica de 1091 amostras da parte superior do testemunho IC2, incluindo $\mathrm{Na}^{+}, \mathrm{K}^{+}, \mathrm{Mg}^{2+}, \mathrm{Ca}^{2+}, \mathrm{Cl}^{-}, \mathrm{NO}_{3}^{-}$e $\mathrm{SO}_{4}^{2}$, O ácido orgânico $\mathrm{H}_{3} \mathrm{CSO}_{3}^{-}$(metanosulfonato - MS-) e o nssSO ${ }_{4}^{2-}$ (excesso de sulfato). As estatísticas básicas calculadas para cada íon são apresentadas na tabela 4.

O excesso de sulfato (ou seja, aquele de origem não marinha, non-sea salt sulphate nssSO ${ }_{4}^{2-}$ ) é derivado das concentrações totais de sulfato em relação à proporcionalidade encontrada na água do mar e foi calculado para cada amostra pela equação 1 (em $\mu g L^{1}$ ), adotada de acordo com a metodologia descrita por Dixon et al. (2004) e Steig et al. (2005):

$\mathrm{nsSSO}_{4}^{2-}=\mathrm{SO}_{4}^{2-}-\left[\left(\mathrm{SO}_{4}^{2-/} \mathrm{Na}^{+}\right)_{\text {água do mar }} \mathrm{x} \mathrm{Na}\right]$

onde: $\mathrm{SO}_{4}^{2-} / \mathrm{Na}^{+}=0,251$

\subsection{Datação}

A datação do testemunho IC-2 foi realizada pela contagem das camadas anuais baseadas nas variações sazonais das concentrações de $\mathrm{Na}^{+}$e 

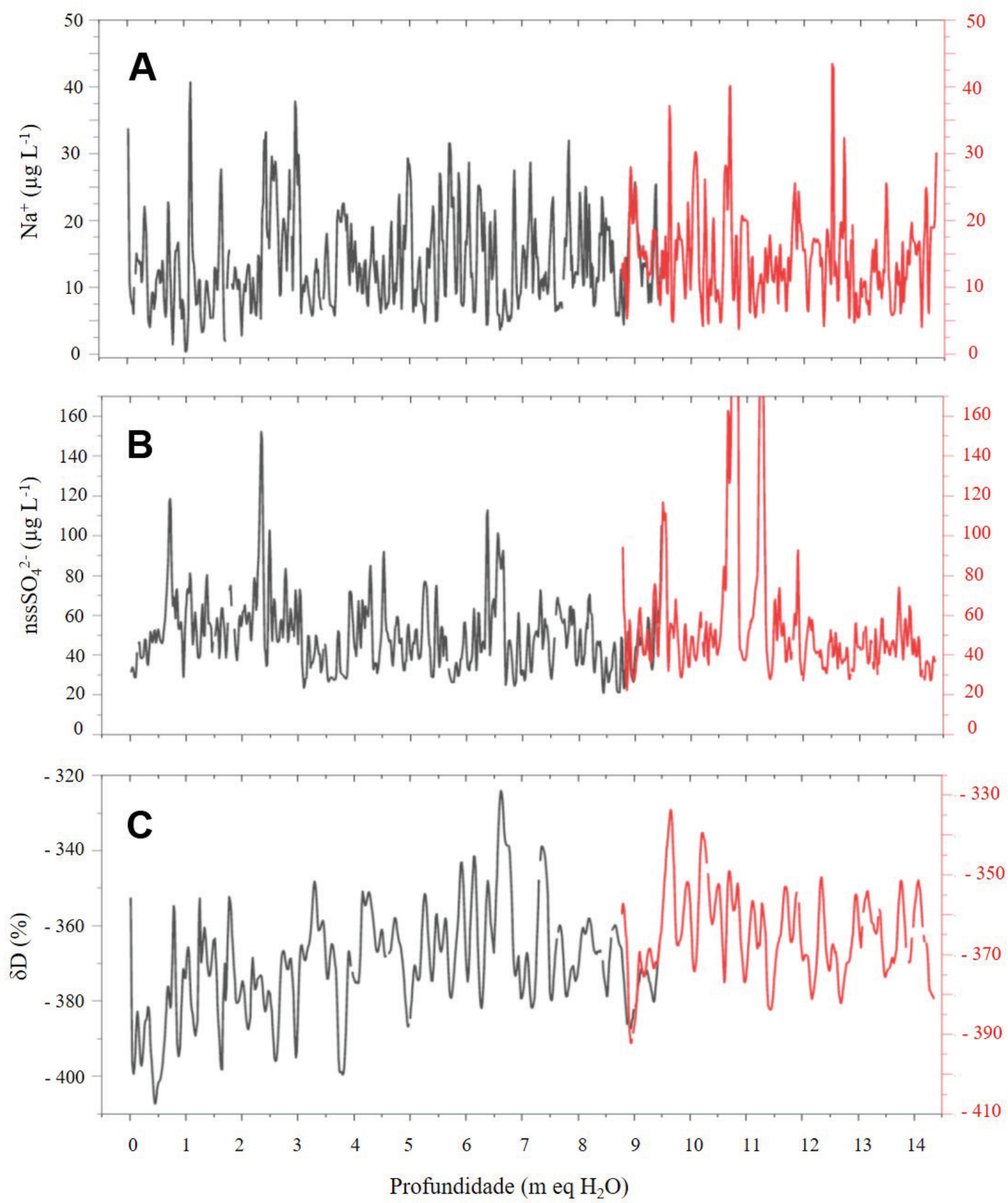

Figura 5. Variação de $\mathrm{Na}^{+}(\mathrm{A}), \mathrm{nssSO}_{4}{ }^{2-}(\mathrm{B})$ e $\delta \mathrm{D}(\mathrm{C})$ nos testemunhos $\mathrm{A}$ (preto) e testemunho B (vermelho). A sobreposição dos dados nos três gráficos indica onde as amostras coletadas são duplicadas.

Figure 5. Variation of $\mathrm{Na}^{+}(A), \mathrm{nssSO}_{4}{ }^{2-}(B)$ and $\delta D(C)$ in the $A$ (black) and $B(r e d)$ cores. The data overlap in the three graphs indicates where the collected samples are duplicated. 
Tabela 4. Estatística básica do conteúdo de íons maiores encontrados no testemunho IC-2 (concentrações em $\mu \mathrm{g}$ $\mathrm{L}^{-1}$ ). Obs.: as concentrações iônicas máximas marcadas com asterisco (*) têm incerteza associada maior que aquela estabelecida em ensaio de performance do método, por estarem fora do intervalo de calibração esperado e adotado. Table 4. Basic statistics of major ions content found in the IC-2 core (concentrations in $\left.\mu g L^{-1}\right)$. Note: The maximum ionic concentrations marked with an asterisk (*) have associated uncertainty greater than that established ones by the method performance test, as they are outside the expected and adopted calibration range.

\begin{tabular}{|c|c|c|c|c|c|c|c|c|c|}
\hline Variável & $\mathrm{Na}^{+}$ & $\mathbf{K}^{+}$ & $\mathrm{Mg}^{2+}$ & $\mathrm{Ca}^{2+}$ & $\mathrm{H}_{3} \mathrm{CSO}_{3}^{-}$ & $\mathrm{Cl}^{-}$ & $\mathrm{NO}_{3}^{-}$ & $\mathrm{SO}_{4}{ }^{2-}$ & $\mathrm{nSSSO}_{4}{ }^{2-}$ \\
\hline Mínimo $\left(\mu \mathrm{g} \mathrm{L}^{-1}\right)$ & $<0,1$ & $<0,1$ & 0,2 & 0,5 & $<0,1$ & 4,0 & 20,1 & 19,4 & 15,5 \\
\hline Máximo $\left(\mu g \mathrm{~L}^{-1}\right)$ & 107,1 & $126,5^{*}$ & 25,7 & 38,6 & 25,7 & 181,2 & 168,7 & $603,7^{*}$ & $599,0^{*}$ \\
\hline Mediana $\left(\mu \mathrm{g} \mathrm{L}^{-1}\right)$ & 12,7 & 2,0 & 1,8 & 3,5 & 2,1 & 33,4 & 69,8 & 48,9 & 45,7 \\
\hline Média $\left(\mu \mathrm{g} \mathrm{L}^{-1}\right)$ & 13,9 & 2,6 & 2,0 & 4,7 & 2,6 & 34,5 & 73,6 & 57,6 & 54,1 \\
\hline Desvio Padrão $\left(\mu \mathrm{g} \mathrm{L}^{-1}\right)$ & 8,7 & 5,0 & 1,1 & 4,2 & 2,2 & 11,1 & 21,4 & 41,2 & 41,3 \\
\hline Número de amostras & 1080 & 1010 & 1083 & 1082 & 873 & 1084 & 1067 & 1074 & 1068 \\
\hline
\end{tabular}

nss $\mathrm{SO}_{4}{ }^{2-}$, em conjunto com as variações da razão isotópica $\delta D$ determinadas por Tavares (2019), conforme a figura 6 , que representa somente os primeiros $28,59 \mathrm{~m}$ reais do testemunho (ou $14,35 \mathrm{~m}$ eq $\mathrm{H}_{2} \mathrm{O}$ ). Todos os dados utilizados na datação foram atenuados pelo cálculo de média móvel de três amostras.

As concentrações de $\mathrm{Na}^{+}$exibem o registro de sua máxima durante o inverno (Legrand \& Mayewski, 1997); o nssSO ${ }_{4}^{2-}$ apresenta seus picos no verão, uma vez que tem como a sua principal fonte a oxidação do dimetilsulfureto (DMS) gerado por organismos marinhos (Kreutz \& Koffman, 2013); e a razão isotópica $\delta \mathrm{D}$ apresenta os máximos relativos no verão (Dansgaard, 1964). Assim, neste trabalho, as contagens anuais deram-se através de baixas relativas de $\mathrm{Na}^{+}$, e altas relativas de $\mathrm{nssSO}_{4}{ }^{2-}$ e $\delta \mathrm{D}$, todos representando registros de verões.

Ao total foram identificados, em $14,35 \mathrm{~m} \mathrm{eq}$ $\mathrm{H}_{2} \mathrm{O}, 85$ anos de registro, abrangendo o período 1918-2003. Como as amostras superficiais foram descartadas, aquela referente ao ano de 2004 não foi analisada. A datação obtida coincide com aquela apresentada por Lindau et al. (2016), que identifica um pico em nssSO ${ }_{4}^{2-}$ a $2,82 \mathrm{~m}$ eq $\mathrm{H}_{2} \mathrm{O}$ como resultante da erupção do Cerro Hudson (Chile) em junho e agosto de 1991, ou do monte Pinatubo (Filipinas) no ano de 1993. Além desse pico, identificou-se o registro da erupção do monte Agung (Indonésia) (ocorrido em março de 1963) no ano de 1965 (o material gerado por erupções inter-hemisféricas leva até 2 anos para chegar à Antártica).
O erro estimado nesta datação é de \pm 3 anos devido às incertezas em alguns picos, que podem trazer registros duplos anuais e, também, apresentar ausência em alguns verões, e à presença de ruídos no registro.

A taxa média de acumulação de neve é 0,15 $\pm 0,06 \mathrm{~m} \mathrm{eq}_{2} \mathrm{O}$ ano $^{-1}$, e está dentro das variações determinadas por Masson-Delmotte et al. (2008), ou seja, entre 4,6 e 23,0 cm eq $\mathrm{H}_{2} \mathrm{O}$ ano-1 $^{-1}$ para a região próxima ao Polo Sul geográfico, onde se encontra o sítio do IC-2.

Na região do sítio do IC-2, foi registrado a presença de áreas com esmalte de gelo na superfície (Lindau et al., 2016), que ocorrem quando o vento e a sublimação removem toda, ou quase toda, a neve precipitada ao longo do ano, acarretando em um balanço superficial de massa variável entre -0,2 e 0,2 m eq água ano-1 (Scambos et al., 2012). Esses eventos levam a neve a áreas próximas, que consequentemente podem apresentar taxas de acumulação de neve maiores do que esperado (Lindau et al., 2016).

\section{Discussão}

\section{1 Balanço iônico}

O balanço iônico, apresentado na figura 7, traz os valores das concentrações médias de cada íon, analisados em micro equivalentes

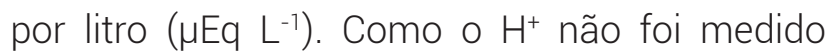
diretamente, ele foi calculado através da equação 2, modificada de Legrand e Mayewski (1997): 


$$
\left[\mathrm{H}^{+}\right]=\left\{[\mathrm{MS}-]+\left[\mathrm{Cl}^{-}\right]+\left[\mathrm{NO}_{3}^{-}\right]+\left[\mathrm{SO}_{4}{ }^{2-}\right]\right\}-\left\{\left[\mathrm{Na}^{+}\right]+\left[\mathrm{K}^{+}\right]+\left[\mathrm{Mg}^{2+}\right]+\left[\mathrm{Ca}^{2+}\right]\right\}
$$

Apesar de o K+ e o MS- não representarem grandes contribuições iônicas (menos de 0,2 $\mu \mathrm{Eq}$ L-1 (Legrand \& Mayewski, 1997), eles foram considerados, com o objetivo de diminuir as incertezas do cálculo.

Assim, foi possível identificar um forte predomínio de contribuições ácidas neste testemunho, pois o $\mathrm{H}^{+}$representa $68,37 \%$ do conteúdo de cátions $\left(2,27 \pm 1 \mu \mathrm{Eq} \mathrm{L}^{-1}\right)$, que vai de encontro com os dados estabelecidos por Legrand (1987), onde identificou um índice de $\mathrm{H}^{+}$ de 3,01 \pm 0,7 $\mu \mathrm{Eq} \mathrm{L}^{-1}$ para o período de 1959-1969 no Polo Sul geográfico.

A soma da média dos íons majoritários é de 6,66 $\mu \mathrm{Eq} \mathrm{L^{-1 }}$, está dentro do esperado, de acordo com Legrand \& Mayewski (1997), que afirmam que a faixa de valores iônicos da Antártica é entre 5 e $30 \mu \mathrm{Eq} \mathrm{L} \mathrm{L}^{-1}$.

\subsection{Concentrações iônicas}

A tabela 4 apresenta as informações estatísticas de mínima, máxima, mediana, média e desvio padrão dos íons de todas as amostras analisadas neste trabalho, que correspondem aos valores publicados para a região, de acordo com a variabilidade espacial e de altitude, segundo Bertler et al. (2005). As figuras 8 e 9 apresentam os gráficos das concentrações iônicas de cada elemento, gerados a partir da atenuação de média móvel de três amostras dos dados iônicos. A profundidade é em $m$ eq $\mathrm{H}_{2} \mathrm{O}$.

Para avaliar as possíveis fontes em comum dos íons, foram calculados os coeficientes da correlação de Pearson (Tab. 5). As correlações mais fortes identificadas são de $\mathrm{Na}^{+} \times \mathrm{Cl}^{-},(r=$ $0,86)$ e $\mathrm{SO}_{4}{ }^{2-} \times \mathrm{nssSO}_{4}{ }^{2-}(r=0,99)$. Correlações fracas são observadas em $\mathrm{Na}^{+} \times \mathrm{Mg}^{2+}(r=0,57)$, $\mathrm{Na}^{+} \times \mathrm{K}^{+}(r=0,43) \mathrm{e} \mathrm{K}^{+} \times \mathrm{Cl}^{-}(r=0,56)$.

\subsubsection{Contribuições crustais}

O cálcio $\left(\mathrm{Ca}^{2+}\right)$ é usualmente considerado um marcador de aerossóis de origem continental, que pode se apresentar em forma de carbonatos insolúveis (como calcita $-\mathrm{CaCO}_{3}$ ) ou carbonatos solúveis (como gipso - $\left.\mathrm{CaSO}_{4}\right)$ (Kreutz \& Koffmann, 2013). Mas no interior da Antártica, a sua contribuição através de aerossóis de sal marinho pode ter a mesma ordem de grandeza que a continental. A entrada de $\mathrm{Ca}^{2+}$ de origem marinha, que apresenta seu máximo no inverno, tende a encobrir a contribuição crustal, que apresenta pico máximo no verão (Legrand \& Mayewski, 1997; Bigler et al., 2006).

Nas análises do testemunho IC-2, o valor obtido da contribuição do cálcio não marinho $\left(\mathrm{nssCa}^{2+}\right.$ ) representa $89,96 \%$ do $\mathrm{Ca}^{2+}$ total analisado, o que indica que neste sítio há uma fonte de poeira mineral muito importante, podendo vir a ser associado às áreas de rocha expostas das montanhas Transantárticas, mas não é possível descartar uma contribuição intercontinental, embora menor. O cálculo do nssCa ${ }^{2+}$ foi realizado com a equação 3 , retirada de Bigler et al. (2006):

$\mathrm{nssCa}^{2+}=\mathrm{c}\left\{\left[\mathrm{Ca}^{2+}\right]-\left[\mathrm{Na}^{+}\right]\left(\mathrm{Ca}^{2+} / \mathrm{Na}^{+}\right)_{\text {água do mar }}\right\}$

onde: $\mathrm{c}=\left[1-\left(\mathrm{Na}^{+} / \mathrm{Ca}^{2+}\right)_{\text {crustal }}\left(\mathrm{Ca}^{2+} / \mathrm{Na}^{+}\right)_{\text {água do mar }}\right]^{-1}$

O valor normativo de $\left(\mathrm{Ca}^{2+} / \mathrm{Na}^{+}\right)_{\text {água do mar }}$ utilizado é de 0,038, de acordo com Bigler et al. (2006) e o valor $\left(\mathrm{Na}^{+} / \mathrm{Ca}^{2+}\right)_{\text {crustal }}$ utilizado é o da média crustal 0,562, conforme Bowen (1979). 0 valor médio de nssCa ${ }^{2+}$ obtido para o IC-2 é de $4,21 \pm 4,28 \mu \mathrm{g} \mathrm{L}^{-1}$.

\subsubsection{Sais marinhos}

Os íons de $\mathrm{Cl}^{-}$e $\mathrm{Na}^{+}$apresentaram uma correlação de Pearson de 0,86, o que indica uma fonte em comum para esses dois íons, sendo esta fonte provavelmente o sal marinho (Legrand \& Mayewski, 1997).

A partir do cálculo de contribuição crustal de $\mathrm{Ca}^{2+}$, foi possível encontrar os valores de contribuição marinha de sódio (ssNa+), conforme Udisti et al. (2012), onde (eq. 4):

$$
\mathrm{ssNa}^{+}=\text {totNa }{ }^{+}-0,562 \mathrm{nssCa}^{2+}
$$




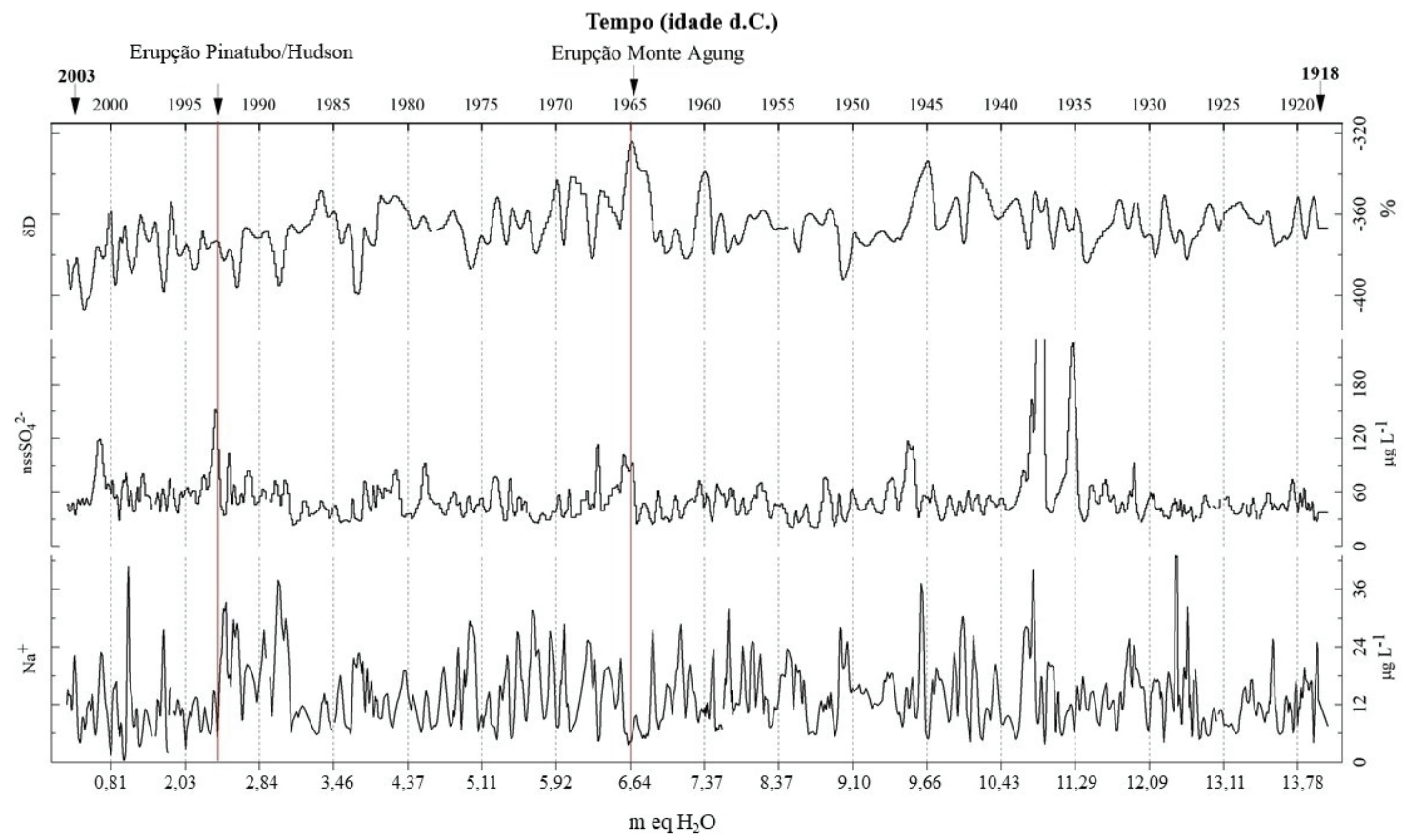

Figura 6. Datação do testemunho IC-2 determinada pela variação sazonal da razão isotópica $\delta D(\%)$ e das concentrações de $\mathrm{nsSO}_{4}{ }^{2-}\left(\mu \mathrm{g} \mathrm{L}^{-1}\right)$ e Na+ $\left(\mu \mathrm{L} \mathrm{L}^{-1}\right)$.

Figure 6. Dating of the IC-2 core determined by the seasonal variation of the isotope ratio $\delta D(\%)$ and the concentrations of $\mathrm{nsSO}_{4}{ }^{2-}\left(\mu \mathrm{g} \mathrm{L}^{-1}\right)$ and $\mathrm{Na}^{+}\left(\mu g \mathrm{~L}^{-1}\right)$.

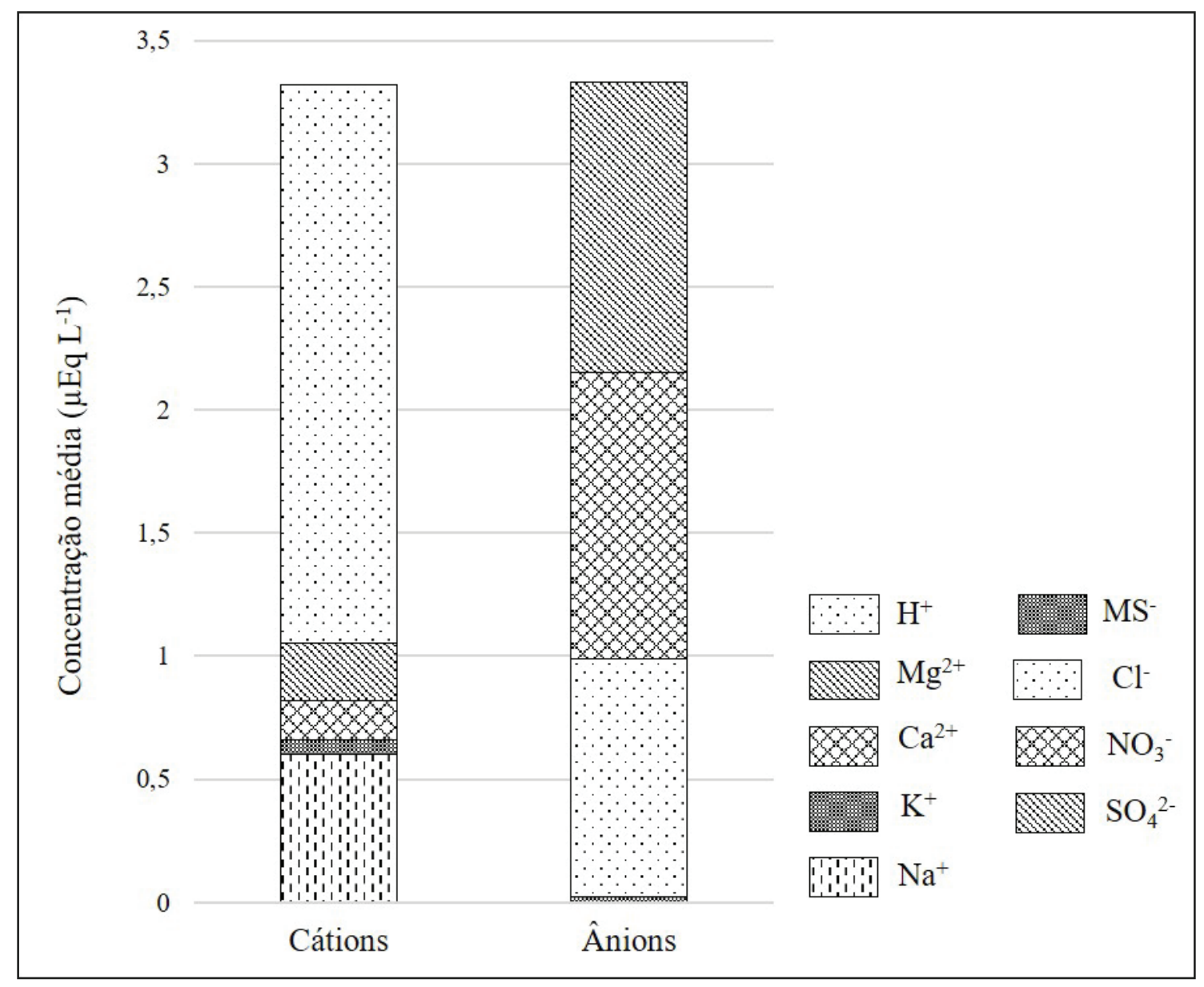

Figura 7. Balanço iônico dos cátions e ânions no testemunho IC-2.

Figure 7. Ionic balance of cations and anions in the IC- 2 core. 


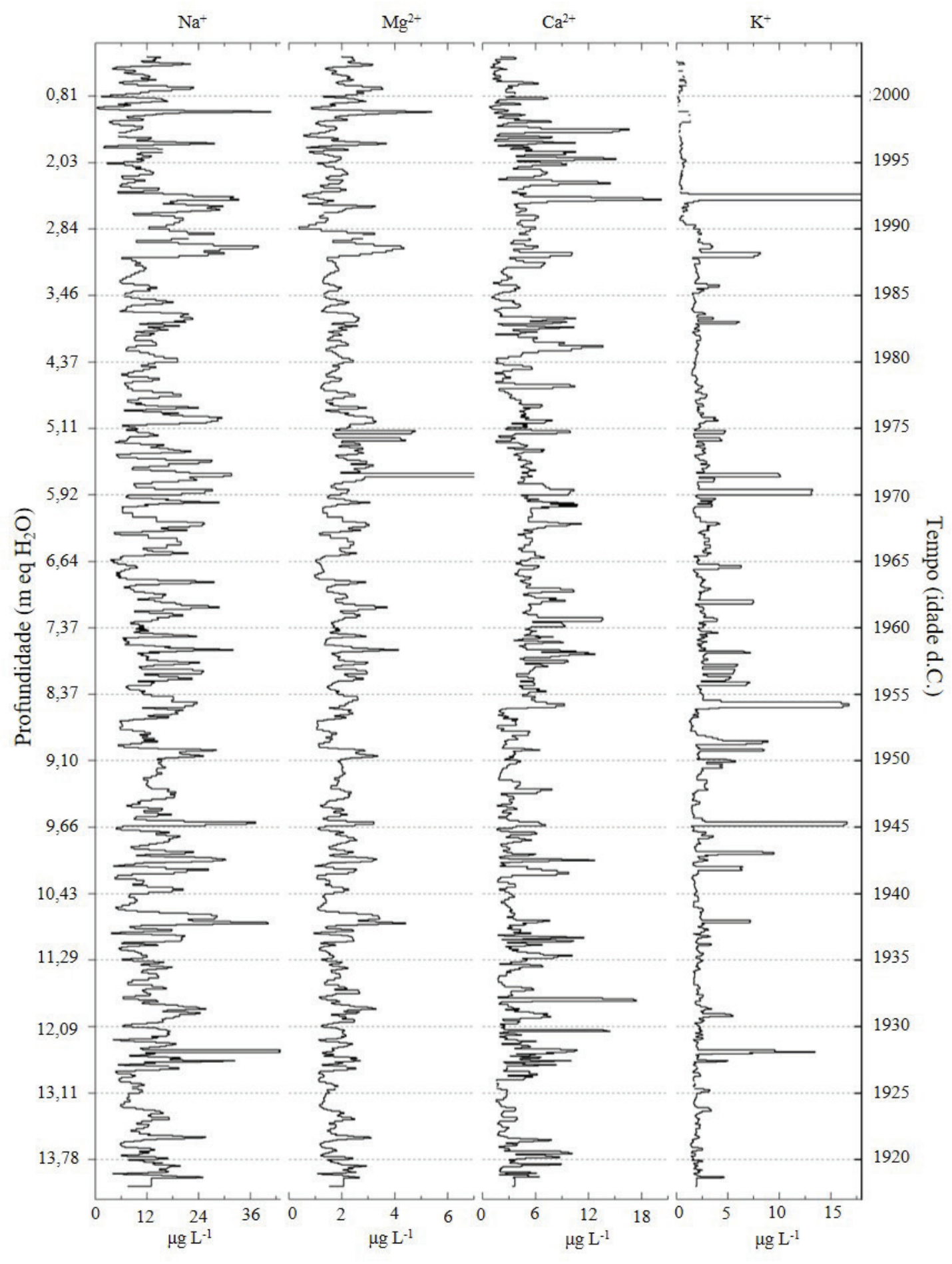

Figura 8. Perfis de $\mathrm{Na}^{+}, \mathrm{Mg}^{2+}, \mathrm{Ca}^{2+}$ e $\mathrm{K}^{+}$para os $28,59 \mathrm{~m}$ (ou 14,35 m eq $\mathrm{H}_{2}$ ) superiores do testemunho IC-2. Valores atenuados com média móvel de 3 amostras.

Figure 8. Profiles of $\mathrm{Na}^{+}, \mathrm{Mg}^{2+}, \mathrm{Ca}^{2+}$ and $\mathrm{K}^{+}$for the upper $28.59 \mathrm{~m}$ (or $14.35 \mathrm{~m} \mathrm{eq} \mathrm{H}_{2} \mathrm{O}$ ) of the IC-2 core). Values smoothed by a 3-samples moving average. 


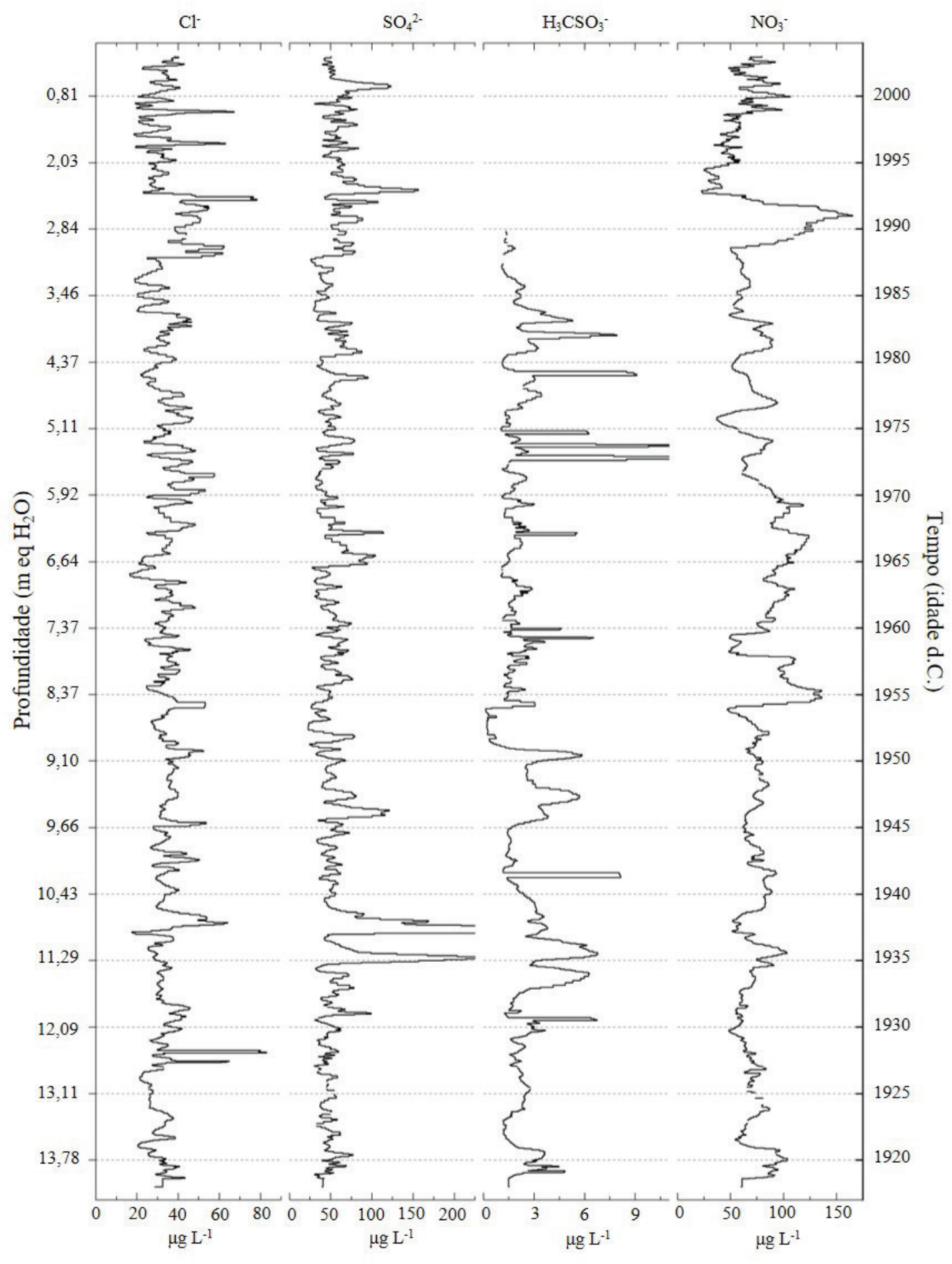

Figura 9. Perfis de $\mathrm{Cl}^{-}, \mathrm{SO}_{4}{ }^{2-}, \mathrm{H}_{3} \mathrm{CSO}_{3}{ }^{-}$e $\mathrm{NO}_{3}-$ para os $28,59 \mathrm{~m}$ (ou $14,35 \mathrm{~m}$ eq $\mathrm{H}_{2} \mathrm{O}$ ) superiores do testemunho IC-2. Valores atenuados com média móvel de 3 amostras.

Figure 9. Profiles of $\mathrm{Cl}^{-}, \mathrm{SO}_{4}{ }_{4}^{2}, \mathrm{H}_{3} \mathrm{CSO}_{3}{ }^{-}$and $\mathrm{NO}_{3}^{-}$for the upper $28.59 \mathrm{~m}$ (or $14.35 \mathrm{~m}$ eq $\mathrm{H}_{2} \mathrm{O}$ ) of the IC-2. Values smoothed by a 3-samples moving average. 
Tabela 5. Coeficientes da correlação de Pearson (r) entre as concentrações iônicas medidas no testemunho IC-2. Table 5. Pearson's correlation coefficients ( $r$ ) between ionic concentrations measured in the IC-2 core.

\begin{tabular}{cccccccccc}
\hline Variável & $\mathbf{N a}^{+}$ & $\mathbf{K}^{+}$ & $\mathbf{M g}^{2+}$ & $\mathbf{C a}^{2+}$ & $\mathbf{H}_{3} \mathbf{C S O}_{3}{ }^{-}$ & $\mathbf{C l}^{-}$ & $\mathbf{N O}_{3}{ }^{-}$ & $\mathbf{S O}_{4}{ }^{2-}$ & $\mathbf{n s s S O}_{4}{ }^{2-}$ \\
\hline $\mathbf{N a}^{+}$ & 1,00 & 0,43 & 0,57 & 0,21 & $-0,01$ & $\mathbf{0 , 8 6}$ & $-0,003$ & 0,04 & $-0,02$ \\
\hline $\mathbf{K}^{+}$ & & 1,00 & 0,17 & 0,31 & $-0,03$ & 0,56 & 0,03 & $-0,02$ & $-0,04$ \\
\hline $\mathbf{M g}^{2+}$ & & & 1,00 & 0,09 & 0,05 & 0,45 & $-0,05$ & 0,03 & $< \pm 0,01$ \\
\hline $\mathbf{C a}^{2+}$ & & & & 1,00 & $< \pm 0,01$ & 0,24 & 0,08 & 0,01 & $< \pm 0,01$ \\
\hline $\mathbf{H}_{3} \mathbf{C S O}^{-}$ & & & & & 1,00 & 0,03 & 0,01 & 0,11 & 0,11 \\
\hline $\mathbf{C l}^{-}$ & & & & & & 1,00 & 0,03 & $-0,02$ & $-0,06$ \\
\hline $\mathbf{N O}_{3}{ }^{-}$ & & & & & & & 1,00 & $-0,04$ & $-0,04$ \\
\hline $\mathbf{S O}_{4}{ }^{-2}$ & & & & & & & & 1,00 & $\mathbf{0 , 9 9 8}$ \\
\hline $\mathbf{n s S S O}_{4}{ }^{2-}$ & & & & & & & & & 1,00 \\
\hline
\end{tabular}

Assim, os valores médios de ssNa+ encontrados foram de 11,41 $\pm 8,73 \mu \mathrm{g} \mathrm{L}-1$, o que representa $82 \%$ do sódio total do testemunho IC2, indicando que a maior fonte de sódio é marinha para este sítio.

Para melhor análise dos íons $\mathrm{Cl}^{-}$e $\mathrm{Na}^{+}$foram desenvolvidos gráficos de correlação (Fig. 10).

A inclinação da reta de regressão linear entre os íons de $\mathrm{Cl}^{-}$e $\mathrm{Na}^{+}$(Fig. 10A) é de 1,10, a nuvem de dispersão dos pontos em 10b demonstra grande concentração de dados acima da reta de proporção desses íons na água do mar $(1,8)$, e o valor da razão $\mathrm{Cl}^{-} / \mathrm{Na}^{+}$é de 4,96.

Então, assumindo que a razão média da água do mar é definida em 1,8 (Warneck, 1988), mas que para altitudes acima de 2.000 m essa razão aumenta significativamente, chegando até a ordem de 20 e que o interior da Antártica apresenta valores médios de 4,3 (Bertler et al., 2005), podemos afirmar que a razão encontrada para o IC-2 está dentro dos limites esperados. Para Bertler et al. (2005), no interior da Antártica Oriental, o $\mathrm{Cl}^{-}$apresenta-se relativamente menos depletado que o $\mathrm{Na}^{+}$, fato que eleva o valor da razão entre os íons. E para Legrand \& Mayewski (1997), a entrada de sal marinho é fortemente diminuída no interior da Antártica, podendo atingir apenas 20 a 35\% do total de conteúdo iônico presente.

Para Pasteris et al. (2014), a razão $\mathrm{Cl}$ - / Na + mostra o máximo de inverno como resultado do fracionamento da precipitação mineral de mirabilita $\left(\mathrm{Na}_{2} \mathrm{SO}_{4} \cdot 10 \mathrm{H}_{2} \mathrm{O}\right)$ em salmoura com gelo marinho antes da formação de aerossóis, processo que ocorre na formação da frost flowers sobre o gelo marinho. Frost flowers são cristais de gelo comumente formados sobre o gelo marinho jovem sob condições calmas. Os cristais de gelo são semelhantes aos da geada branca (escarcha) e costumam crescer em segmentos com cerca de 3 a $4 \mathrm{~cm}$ de diâmetro. As frost flowers têm salinidade extremamente alta e devido à sua área superficial relativamente grande, são eficientes liberadores de $\mathrm{HCl}$ durante o inverno.

Conforme Legrand \& Mayewski (1997), a presença de $\mathrm{Na}^{+}$e $\mathrm{Cl}^{-}$como sais marinhos nas camadas de inverno na neve e no gelo do interior antártico é clara, mas há adição de $\mathrm{HCl}$ durante o verão, levando a um valor máximo da razão e a uma variação sazonal mais fraca quando comparado ao $\mathrm{Na}^{+}$. Segundo Dixon et al. (2013), o $\mathrm{Cl}^{-}$marinho é emitido para a troposfera inferior, onde reage para formar o $\mathrm{HCl}$ e é transportado para áreas mais distantes pela troposfera superior. Já as espécies de $\mathrm{Cl}^{-}$encontradas na estratosfera são provenientes de emissões vulcânicas e atividades antrópicas.

A entrada de $\mathrm{HCl}$ no verão pode explicar a outra fonte de $\mathrm{Cl}^{-}$esperada e juntamente com a menor depleção do $\mathrm{Cl}^{-}$e a diminuição da entrada de sal marinho no interior do continente, é o que pode estar levando ao aumento da razão observada no IC-2. 

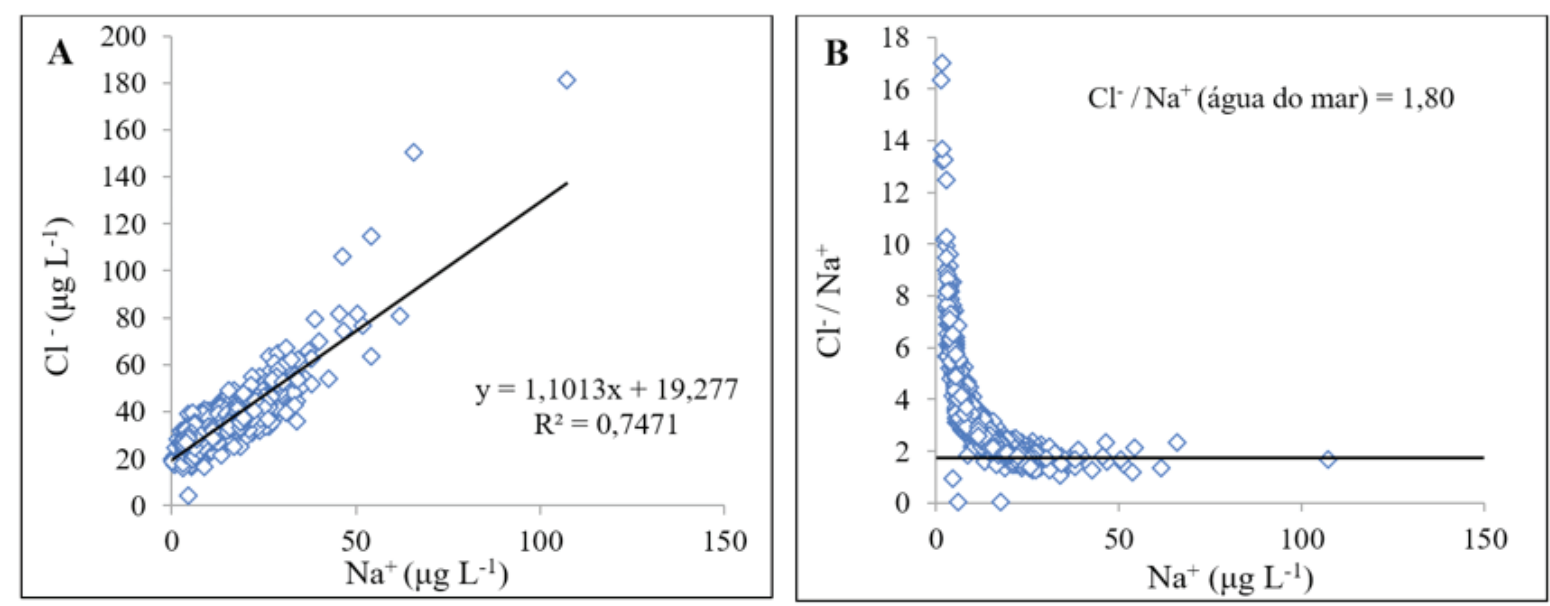

Figura 10. A relação entre as concentrações de $\mathrm{Cl}^{-}$e $\mathrm{Na}^{+}$no testemunho IC-2. A) Gráfico de correlação linear entre $\mathrm{Cl}^{-}$e $\mathrm{Na}^{+}$. A linha em preto é a reta de tendência dos dados. B) Proporção $\mathrm{Cl}^{-} / \mathrm{Na}^{+}$em função de $\mathrm{Na}^{+}$. A linha em preto representa a proporção entre os íons na água do mar.

Figure 10. The relationship between the $\mathrm{Cl}^{-}$e $\mathrm{Na}^{+}$concentrations in the IC-2 core: A) Linear correlation graph between $\mathrm{Cl}^{-}$and $\mathrm{Na}^{+}$. Black line is the data trend line. B) $\mathrm{Cl}^{-} / \mathrm{Na}^{+}$ratio as a function of $\mathrm{Na}^{+}$. The black line represents the ionic ratio in seawater.

Já as correlações $\mathrm{Na}^{+} \times \mathrm{K}^{+}$e $\mathrm{Na}^{+} \times \mathrm{Mg}^{2+}$ apresentam valores baixos (Tab. 5). Mas pelos perfis iônicos é possível identificar que as máximas dos picos de $\mathrm{K}^{+}$e $\mathrm{Mg}^{2+}$ coincidem com as máximas de $\mathrm{Na}^{+}$, o que mantém o sal marinho como fonte principal desses íons. As correlações fracas podem ser explicadas devido aos valores medidos, principalmente para o $\mathrm{K}^{+}$, estarem muito próximos dos limites de detecção do método utilizado, que pode ser observado na tabela 3, devido ao erro negativo registrado na análise.

\subsubsection{Sulfato e contribuições biogênicas: $\mathrm{nsSOO}_{4}{ }^{2-}$ e MS-}

As contribuições biogênicas tem um papel muito importante no ciclo atmosférico do enxofre, uma vez que a oxidação do dimetilsulfureto (DMS) emitido pelos fitoplâncton marinho no verão representa a maior fonte de $\mathrm{nssSO}_{4}{ }^{2-} \mathrm{e}$ a única fonte de $\mathrm{MS}^{-}$, o metanosulfonato (ou $\mathrm{H}_{3} \mathrm{CSO}_{3}^{-}$) (Sneed et al., 2011; Kreutz \& Koffman, 2013).

A presença do $\mathrm{SO}_{4}{ }^{2-}$ no gelo pode ser associada às entradas primárias de sal marinho, influências continentais que trazem $\mathrm{CaSO}_{4} \mathrm{e}$ também à presença de $\mathrm{H}_{2} \mathrm{SO}_{4}$ produzido na oxidação atmosférica do $\mathrm{SO}_{2}$, que é introduzido na atmosfera em erupções vulcânicas, por atividades humanas e pela oxidação de vários componentes de enxofre emitidos pela biosfera
(Legrand \& Mayewski, 1997). O SO ${ }_{4}^{2-}$ marinho biogênico é transportado para o continente antártico através da troposfera inferior e superior, e $\mathrm{O} \mathrm{SO}_{4}{ }^{2-}$ oriundo de atividades vulcânicas e antropogênicas é transportado principalmente pela estratosfera (Dixon et al., 2013).

$\mathrm{O}$ excesso de sulfato ( $\mathrm{nssSO}_{4}{ }^{2-}$ ) calculado no IC-2 representa $93,94 \%$ do $\mathrm{SO}_{4}{ }^{2-}$ total, o que significa que apenas $6,06 \%$ do sulfato encontrado no IC-2 é proveniente de sal marinho.

O MS $^{-}$representa somente $0,44 \%$ do conteúdo iônico total do IC-2, decorrente da diminuição sutil das concentrações deste íon em direção ao centro da Antártica e, também, com o aumento da altitude local (Becagli et al., 2004).

Apesar da contribuição de MS $^{-}$não ser muito significativa, a concentração de nssSO ${ }_{4}^{2-e ́}$ elevada, e diante disto é possível afırmar que no sítio do IC-2 há uma contribuição não apenas marinha, mas também de aerossóis secundários provenientes da oxidação de gases precursores como $\mathrm{O} \mathrm{SO}_{2}$ tanto na troposfera como na estratosfera (Dixon et al., 2004). Na análise do perfil estratigráfico de excesso de sulfato é possível observar o aumento nos níveis desse ín quando há registros de erupções vulcânicas. Outras influências continentais também podem estar elevando os valores de nssSO ${ }_{4}^{2-}$, como a entrada de aerossóis que contenham gipso ou anidrita. 


\subsubsection{Nitrato}

A partir do cálculo dos coeficientes da correlação de Pearson (Tab. 4) é possível observar que o nitrato não apresenta correlação com os outros íons analisados. Isso porque é um aerossol secundário, que não tem o oceano como fonte e seus processos de formação são complexos, podendo vir de múltiplas fontes (Thoen et al., 2018). Conforme Bertler et al. (2005), o nitrato pode ser produzido na estratosfera por oxidação de $\mathrm{N}_{2} \mathrm{O}$ e pelas nuvens polares através do $\mathrm{HNO}_{3^{\prime}}$ e na ionosfera por dissociação de $\mathrm{N}_{2}$.

De acordo com Röthlisberger et al. (2002), as concentrações de nitrato aumentam conforme as temperaturas locais diminuem (regiões mais frias apresentam maiores valores de $\mathrm{NO}_{3}^{-}$). Mas, quando há taxas muito baixas de precipitação de neve locais, como no caso da região do Domo $\mathrm{C}$, esta regra não é válida, sendo encontradas taxas menores, que diminuem do topo para a base do manto de gelo (com concentrações que variam de 1000 ppb até 15 pbb) (Röthlisberger et al., 2002). $\mathrm{E}$ alguns processos pós deposicionais podem levar a perdas muito significativas de $\mathrm{NO}_{3}$ - pelo fracionamento isotópico, principalmente onde as taxas de acumulação são baixas (Laluraj et al., 2010), como ocorre no sítio do testemunho IC-2.

Assim, os valores de concentração média de $\mathrm{NO}_{3}{ }^{-}$encontrados no IC-2, que são de 73,57 $\mu \mathrm{g} \mathrm{L}{ }^{1}$, com desvio padrão de 21,39 $\mu \mathrm{g}$ $\mathrm{L}^{-1}$, vão de encontro à esses dados, indicando que a baixa precipitação local e os processos pós-deposicionais podem estar afetando as concentrações neste sítio.

A variabilidade das concentrações de $\mathrm{NO}_{3}{ }^{-}$apresenta um aspecto importante quando relacionada ao efeito do $\mathrm{SO}_{4}{ }^{2-}$ nas erupções vulcânicas, que mostram um enriquecimento logo após o pico das concentrações de nitrato, indicando que na recristalização, a acumulação de nitrato sucede a deposição de sulfato (Laluraj et al., 2010). Este efeito é observado no registro do ano de 1993 no IC-2, que possivelmente representa a erupção do Pinatubo e/ou Cerro Hudson. Na figura 9 percebe-se claramente enriquecimento de sulfato logo após os picos de nitrato.

\subsection{Eventos significativos}

Os perfis iônicos nos permitem identificar os picos de concentrações mais altas e também as suas durações. Conforme afirmam Thoen et al. (2018), eles são associados a importantes eventos ocorridos em condições climáticas atípicas. Na Antártica, os eventos vulcânicos são identificados por um relativo aumento na linha de base das concentrações de sulfato (Sneed et al., 2011).

No perfil iônico do nssSO ${ }_{4}{ }^{2-}$, apresentado na figura 6, de datação do testemunho, os três primeiros picos significativos identificados, que são inclusive os maiores picos em todo o registro, são em 1935, 1938 e 1939. A hipótese de contaminação do testemunho foi descartada, pois é observado um aumento gradativo das concentrações a partir da análise do perfil estratigráfico gerado. De acordo com Kurbatov et al. (2006), a única erupção vulcânica que poderia explicar este aumento de sulfato não-marinho é relacionada a erupção de Bristol Island, na Antárctica, ocorrida no ano de 1935, que apresentou um índice de explosividade vulcânica (em inglês, VEI) de 2.

$\mathrm{Na}$ sequência do perfil estratigráfico é identificado um pico de nssSO ${ }_{4}^{2-}$ no ano de 1965, que pode representar o registro da erupção do vulcão Agung, localizado na Indonésia, que ocorreu no ano de 1963, com um VEI de 5 (Kurbatov et al., 2006), e um outro pico, registrado em 1993, que pode representar as erupções do Monte Pinatubo (Filipinas) e/ou do Cerro Hudson (Chile), ambas ocorridas no ano de 1991, com VEI de 6 e 5 , respectivamente.

\section{Conclusões}

A taxa média de acumulação de neve mostra-se dentro do esperado para este sítio, de acordo com Masson-Delmotte et al. (2008) e as estatísticas básicas dos íons correspondem aos valores publicados para a região (Bertler et al., 2005). Os padrões sazonais de $\mathrm{Na}^{+}$e nssSO ${ }_{4}{ }^{2-}$ (juntamente com $\delta \mathrm{D}$ ) nos perfis estratigráficos permitiram uma boa determinação de idade e cálculo de taxa de acumulação para o sítio do IC-2. A identificação de registros de erupções 
vulcânicas no testemunho IC-2 permitiu que a idade do testemunho obtida fosse confirmada. Erupções foram registradas em 1993, referente às erupções do Pinatubo e / ou Cerro Hudson, 1965, referente ao Monte Agung, e possivelmente 1936, referente à Bristol Island.

Através da análise do ss $\mathrm{Na}^{+}$pode-se observar que mais de $80 \%$ do $\mathrm{Na}^{+}$presente no IC2 é de origem marinha e com a correlação dos picos de $\mathrm{K}^{+}$e $\mathrm{Mg}^{2+}$ com os de $\mathrm{Na}^{+}$, foi possível identificar que a sua principal fonte destes íons é também o sal marinho. Como as concentrações de $\mathrm{Cl}^{-}$são elevadas em relação ao $\mathrm{Na}^{+}$nesse sítio, interpretou-se que ao mesmo tempo que a entrada de sal marinho no interior da Antártica é reduzida, $\mathrm{o} \mathrm{Cl}^{-}$apresenta outras fontes, como de $\mathrm{HCl}$, e é menos depletado quando comparado ao $\mathrm{Na}^{+}$. Já o $\mathrm{Ca}^{2+}$ tem origem predominantemente crustal, que pode ser oriunda de poeira crustal das rochas expostas das montanhas Transantárticas. $\mathrm{O} \mathrm{SO}_{4}{ }^{2-}$ tem valores que mostram uma forte contribuição marinha biogênica no verão e também sinais de vulcanismo local e global. 0 $\mathrm{NO}_{3}^{-}$não apresenta correlação com os outros íons por ser um aerossol secundário sem origem marinha, mas é verificado, na variabilidade das suas concentrações, picos que antecedem os picos de sulfato no registro de erupções vulcânicas. Os valores de nitrato mostramse baixos, confirmando a influência local pela baixa taxa de precipitação de neve e possíveis alterações pós-deposicionais.

Os resultados apresentados aqui complementam o entendimento químico da região através das análises dos outros testemunhos coletados nesta travessia Antártica.

Agradecimentos. Este estudo é parte das investigações do Programa Antártico Brasileiro (PROANTAR) e foi financiado por projetos de pesquisa do Conselho Nacional de Desenvolvimento Científıco e Tecnológico (CNPq), Processos 558117/2005-8 e 557053/2009- 9 e do Instituto Nacional de Ciência e Tecnologia da Criosfera (CNPq Processo 465680/2014-3). Os trabalhos de campo foram uma ação colaborativa do Centro de Estudios Científicos de Valdívia (Chile) e do Centro Polar e Climático da UFRGS e contou com o apoio logístico do Exército do Chile e da Força Aérea Chilena (FACh).

\section{Referências}

Becagli, S., Proposito, M., Benassai, S., Flora, O., Genoni, L., Gragnani, R., Largiuni, O., Pili, S.L., Severi, M., Stenni, B., Traversi, R., Udisti, R. \& Frezzotti, M. 2004. Chemical and isotopic snow variability in East Antarctica along the 2001/02 ITASE traverse. Annals of Glaciology, 39: 473-482.

Bertler, N., Mayewski. P.A., Aristarin, A., Barrett, P., Becagli, S., Bernardo, R., Bo, S., Xiao, C., Curran, M., Qin, D., Dixon, D., Ferron, F., Fischer, H., Frey, M., Frezzotti, M., Fundel, F., Genthon, C., Gragnani, R., Hamilton, G., Handley, M., Hong, S., Isaksson, E., Kang, J., Ren, J., Kamiyama, K., Kanamori, S., Kärkäs, E., Karlöf, L., Kaspari, S., Kreutz, K., Kurbatov, A., Meyerson, E., Ming, Y., Zhang, M., Motoyama, H., Mulvaney, R., Oerter, H., Osterberg, E., Proposito, M., Pyne, A., Ruth, U., Simões, J., Smith, B., Sneed, S., Teinilä, K., Traufetter, F., Udisti, R., Virkkula, A., Watanabe, O., Williamson, B., Winther, J-G., Li, Y., Wolff, E., Li, Z. \& Zielinski, A. 2005. Snow chemistry across Antarctica. Annals of Glaciology, 41: 167-179.

Bigler, M., Röthlisberger, R., Lambert, F., Stocker, T.F. \& Wagenbach, D. 2006. Aerosol deposited in East Antarctica over the last glacial cycle: Detailed apportionment of continental and sea-salt contributions. Journal of Geophysical Research, 111: D08205.

Bowen, H. 1979. Environmental chemistry of the elements. Londres, Academic Press, 333p.

Candelone, J.-P., Hong, S. \& Boutron, C. F. 1994. An improved method for decontaminating polar snow or ice cores for heavy metal analysis. Analytica Chimica Acta, 299: 9-16.

Cuffey, K.M. \& Paterson, W.S.B. 2010. The Physics of Glaciers. Oxford, Pergamon/Elsevier, 704p.

Dansgaard, W. 1964. Stable Isotopes in precipitation. Tellus, 16(4): 436-468;

Dixon, D., Mayewski, P.A., Kaspari, S., Sneed, S. \& Handley, M.J. 2004. A 200-year sub-annual record of sulfate in West Antarctica from 16 ice cores. Annals of Glaciology, 39: 545-556.

Dixon, D., Mayewski, P.A., Korotkikh, E., Sneed, S., Handley, M.J., Introne, D.S. \& Scambos, T.A. 2013. Variations in snow and firn chemistry along US ITASE traverses and the effect of surface glazing. The Cryosphere, 7: 515-535. 
Jouzel, J. 2013. A brief history of ice core science over the last 50 yr. Climate of the Past, 9: 25252547.

Kreutz, K.J. \& Koffman, B.G. 2013. Glaciochemistry. In: Scott, A.E. \& Mock, C.J. Encyclopedia of Quaternary Science, Oxford, Elsevier, 2: 326333

Kurbatov, A.V., Zielinski, G.A., Dunbar, N.W., Mayewski, P.A., Meyerson, E.A., Sneed, S.B. \& Taylor, K.C. 2006. A 12,000 year record of explosive volcanism in the Siple Dome Ice Core, West Antarctica. Journal of Geophysical Research: Atmosphere, 111: D12307.

Laluraj, C.M., Thamban, M., Naik, S.S., Redkar, B.L., Chaturvedi, A. \& Ravindra, R. 2010. Nitrate records of a shallow ice core from East Antarctica: Atmospheric processes, preservation and climatic implications. The Holocene, 21(2): 351-356.

Legrand, M. 1987. Chemistry of Antarctic Snow and Ice. Journal de Physique, 48 (C1): 77-86.

Legrand, M. \& Mayewski, P. 1997. Glaciochemistry of polar ice cores: a review. Reviews of Geophysics, 35(3): 219-243.

Lindau, F.G.L., Simões, J.C., Marques, M.M., Hammes, D.F., Silva, D.B., Casassa, G., Sneed, S. \& Introne, D. 2016. Variabilidade do conteúdo iônico da neve e do firn ao longo de um transecto antártico. Pesquisas em Geociências, 43(3): 213-228.

Masson-Delmotte, V., Hou, S., Ekaykin, A., Jouzel, J., Aristarain, A., Bernardo, R.T., Bromwich, D., Cattani, O., Delmotte, M., Falourd, S., Frezzotti, M., Gallée, H., Genoni, L., Isaksson, E., Landais, A., Helsen, M.M., Hoffmann, G., Lopez, J., Morgan, V., Motoyama, H., Noone, D., Oerter, H., Petit, J.R., Royer, A., Uemera, R., Schmidt, G.A., Schlosser, E., Simões, J.C., Steig, E.J., Stenni, B., Stievenard, M., van den Broeke, M.R., van de Wal, R.S.W., van de Berg, W.J., Vimeux, F. \& White, J.W.C. 2008. A review of Antarctic surface snow isotopic composition: Observations, atmospheric circulation, and isotopic modeling. Journal of Climate, 21: 3359-3387.

Mayewski, P.A. \& Goodwin, D. 1997. International Trans-Antarctic Scientific Expedition (ITASE) - "200 years of Past Antarctic Climate and Environmental Change". PAGES-SCAR
Workshop Report Series, 97-7. Berna, Suíça, $48 \mathrm{p}$.

Osterberg, E.C., Handley, M.J., Sneed, S.B., Mayewski P.A. \& Kreutz, K.J. 2006. Continuous ice core melter system with discrete sampling for major ion, trace element, and stable isotope analyses. Environmental Science and Technology, 40(10): 3355-336.

Pasteris, D. R., McConnell, J.R., Das, S.B., Criscitiello, A.S., Evans, A.S., Maselli, O.J, Sigl, M. \& Layman, L. 2014. Seasonally resolved ice core records from West Antarctica indicate a sea ice source of sea-salt aerosol and a biomass burning source of ammonium. Journal of Geophysical Research: Atmosphere, 119: 9168-9182.

Röthlisberger, R., Hutterli, M.A., Wolff, E.W., Mulvaney, R., Fischer, H., Bigler, M., GotoAzuma, K., Hansson, M.E., Ruth, U., SiggaardAndersen, M.-L. \& Steffensen, J.P. 2002. Nitrate in Greenland and Antarctic ice cores: a detailed description of post-depositional processes. Annals of Glaciology, 35: 209-216. Scambos, T., Frezzotti, M., Haran, T., Bohlander, J., Lenaerts, J., van der Broeke, M., Jezek, K., Long, D., Urbini, S., Farness, K., Neumann, T., Albert, M. \& Winther, J. 2012. Extent of lowacumulation 'wind glaze' areas on the East Antarctic plateau: implications for continental mass balance. Journal of Glaciology, 58(210): 633-647.

Schwanck, F. 2012. Determinação de elementos traços em testemunho de firn Antártico usando espectrometria de massa. Porto Alegre, 134p. Dissertação de Mestrado, Programa de PósGraduação em Geociências, Instituto de Geociências, Universidade Federal do Rio Grande do Sul.

Silva, D.B. 2011. Interpretação ambiental por cromatografia iônica de um testemunho de firn da Antártica. Porto Alegre, 100p. Dissertação de Mestrado, Programa de Pós-Graduação em Geociências, Instituto de Geociências, Universidade Federal do Rio Grande do Sul.

Sneed, S.B., Mayewski, P.A. \& Dixon, D.A. 2011. An emerging technique: multi-ice-core multiparameter correlations with Antarctic sea-ice extent. Annals of Glaciology, 52(57): 347- 354. Steig, E.J., Mayewski, P.A., Dixon, D.A., Kaspari, 
S.D., Frey, M.M., Schneider, D.P., Arcone, S.A., Hamilton, G.S., Spikes, V.B., Albert, M., Meese, D., Gow, A.J., Shuman, C.A., White, J.W.C., Sneed, S., Flaherty, J. \& Wumkes, M. 2005. High-resolution ice cores from US ITASE (West Antarctica): development and validation of chronologies and determination of precison and accuracy. Annals of Glaciology, 41: 77-84.

Tavares, F.A. 2019. Interpretação ambiental das razões de isótopos estáveis em um testemunho de firn do manto de gelo da Antártica. Porto Alegre, 77p. Dissertação de Mestrado, Programa de Pós-Graduação em Geociências, Instituto de Geociências, Universidade Federal do Rio Grande do Sul.

Thoen, I.U. 2017. Conteúdo iônico em testemunho de firn/gelo do Monte Johns. Antártica Ocidental: 1882-2008 A.D. Porto Alegre, 132p. Dissertação de Mestrado, Programa de Pós-Graduação em Geociências, Instituto de Geociências, Universidade Federal do Rio Grande do Sul.

Thoen, I.U., Simões, J.C., Lindau, F.G.L. \& Sneed, S.B. 2018. Ionic content in an ice core from the West Antarctic Ice Sheet: 1882-2008 A.D. Brazilian Journal of Geology, 48(4): 853-865.

Udisti, R., Dayan, U., Becagli, S., Busetto, M., Frosini, D., Legrand, M., Lucarelli, F., Preunkert, S., Severi, M., Traversi, R., Vitale, V. 2012. Sea spray aerosol in central Antarctica. Present atmospheric behaviour and implications for paleoclimatic reconstructions. Atmospheric Environment, 52: 109-120.

Warneck, P. 1988. Chemistry of the natural atmosphere. San Diego, Academic Press, $757 p$.

Wolff, E.W. 2012. Chemical signals of past climate and environment from polar ice cores and firn air. Chemical Society Reviews, 41: 6247-6258. 